\title{
The Effect of Perforation on the Dynamics of a Flexible Panel
}

\author{
A. Putra, Y. M. Cheah, N. Muhammad, A. Rivai, and C. M. Wai \\ Centre for Advanced Research on Energy, Universiti Teknikal Malaysia Melaka, Hang Tuah Jaya, \\ 76100 Durian Tunggal, Melaka, Malaysia \\ Correspondence should be addressed to A. Putra; azma.putra@utem.edu.my
}

Received 22 May 2014; Revised 29 August 2014; Accepted 31 August 2014; Published 17 September 2014

Academic Editor: Akira Ikuta

Copyright (c) 2014 A. Putra et al. This is an open access article distributed under the Creative Commons Attribution License, which permits unrestricted use, distribution, and reproduction in any medium, provided the original work is properly cited.

Introduction of holes into plate-like structures is commonly found as one of the practical noise control measures to reduce sound radiation. However, perforation also reduces the panel stiffness and hence increases its vibration. The discussion on this effect is lacking and hence this paper discusses the dynamics of a perforated panel from the results obtained from Finite Element (FE) model. Different hole geometries and arrangement are simulated to investigate their effect on the plate mobility. In general, it is found that increasing the perforation ratio increases the plate mobility. For a fixed perforation ratio, the mobility increases at high frequency (above $1 \mathrm{kHz}$ ) for a smaller hole density in the plate. The plate with holes concentrated at the middle shows the largest increase of vibration around the plate centre compared to those uniformly distributed or away from the middle and concentrated at the plate edges. This is because as the hole separation becomes smaller, the reduction of the global stiffness around the mid area of the plate becomes greater. This also corresponds to the finding here that the mobility is greater at the vicinity of the hole. Different conditions of the plate edges are found to give consistent trend of the effect of perforation.

\section{Introduction}

The vibration of engineering structures, particularly those consisting of thin plate-like members, can be a significant source of noise in many situations. It is common in noise control technique to reduce the sound radiation of such structures directly by constructing them from perforates. This technique is known to be capable of reducing considerable noise radiation and has found many practical applications, including safety guard enclosures over flywheels and producing collection hoppers.

However, the effect of perforation on the plate dynamics is rarely discussed, at least in terms of change in the vibration level due to perforation. The recent models $[1,2]$ to calculate the sound radiation from a perforated panel also ignore this effect. The investigation of the effect of perforation on dynamic properties of plates began in the early 1960s in order to determine an accurate stress analysis of perforated panels used to support the tubes in a heat exchanger $[3,4]$. To obtain equivalence with the actual properties corresponding to a solid plate, the effective material properties were defined, namely, effective Young's modulus, effective Poisson's ratio, and effective density.

Soler and Hill [5] later proposed an analytical formula to calculate the bending stiffness of a perforated panel as a function of hole geometry. The formula, however, is only valid for small perforation ratio. Forskitt et al. [6] used the Finite Element Method (FEM) to obtain the dynamic properties, namely, Young's modulus and Poisson's ratio of a perforation with circular holes. The density is calculated based on the fraction of a solid plate. These properties are then used to calculate the natural frequencies of the perforated panel.

According to Burgemeister and Hansen [7], the equation proposed in [6] does not provide correct resonant frequencies when the effective material properties are used. The FEM was then implemented to model the modal response of range of plates with varying perforation geometries, where, from here, the resonant frequencies of the perforated plates were obtained. The resonant frequencies were then compared with that from the FEM model for the solid plate. The results of these comparisons were then fitted to a cubic expression as a general equation for other perforation geometries which is independent of the mode order of the panel. 
Patil et al. [8] also used a curve fitting technique to develop an effective resonant frequency formula from simulation data for five perforated plates using FEM. The formula was a function of the so-called mass remnant ratio (MR), that is, the ratio of surface area of a perforated plate to that of the solid plate for the same dimension. The formula was then expressed as a seventh order polynomial function of MR. However, the formula was applicable only for the first three modes of vibration.

Recently, Mali and Singru [9] proposed a technique using concentrated negative mass in the Galerkin method to model the natural frequency of a perforated plate. It is shown that the analytical results are in good agreement with those from a FEM model, but only for small size of holes.

As previous works were concerned with only the dynamic properties of the perforation, this paper investigates the change of vibration level due to the introduction of holes into a solid panel. As no established analytical model is available to calculate the mobility of the perforation, the numerical model is therefore implemented using Finite Element Method (FEM). The numerical calculation of mobility of the perforation is then compared against that of the solid plate in one-third octave band frequency.

\section{Mobility}

2.1. Theoretical Model. Mobility is defined as the ratio between the vibration velocity $v$ and the excitation force $F$ given as a function of frequency, $Y(\omega)=v(\omega) / F(\omega)$. For a finite rectangular plate with dimensions $a \times b$, the mobility at an arbitrary point $(x, y)$ subjected to a point force $F$ at $\left(x_{o}, y_{o}\right)$ is given by [10]

$$
Y(\omega)=j \omega \sum_{n=1}^{\infty} \frac{\Phi_{n}\left(x_{o}, y_{o}\right) \Phi_{n}(x, y)}{\omega_{n}^{2}(1+j \eta)-\omega^{2}},
$$

where $\Phi_{n}$ is the $n$th mass-normalized mode shape of the structure, $\omega_{n}$ is the $n$th natural frequency, and $\eta$ is the damping loss factor. A case often considered is that of a rectangular plate with simply supported boundary conditions as this system provides a simple analytical solution. For a simply supported rectangular plate, the mode shape can be represented by sine functions. This and the natural frequency for mode $(p, q)$ are, respectively,

$$
\begin{gathered}
\Phi_{p q}(x, y)=\frac{2}{\sqrt{M}} \sin \left(\frac{p \pi x}{a}\right) \sin \left(\frac{q \pi x}{b}\right), \\
\omega_{p q}=\sqrt{\frac{B}{M}}\left[\left(\frac{p \pi}{a}\right)^{2}+\left(\frac{q \pi}{b}\right)^{2}\right],
\end{gathered}
$$

where $M$ is the total mass of the plate, $m$ is the mass per unit area, and $B=E t^{3} / 12\left(1-v^{2}\right)$ is the plate bending stiffness for $E$ is Young's modulus, $t$ is the plate thickness, and $v$ is Poisson's ratio. The next section discusses the FE model used to calculate the mobility of the perforated plate.

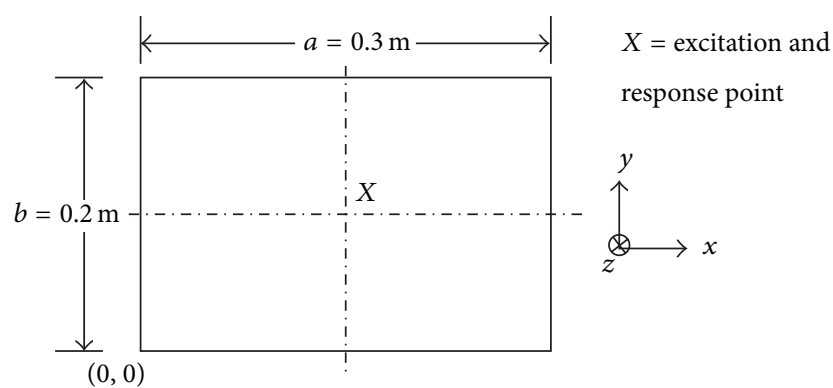

FIGURE 1: Schematic diagram of the panel and the excitation point.

\subsection{Finite Element (FE) Model}

2.2.1. Validation with Theory. The model of the perforated panel is developed here using PATRAN and NASTRAN software programs. In order to ensure the FE model used is valid in terms of the element size and setting of the boundary condition, the result is validated against the theoretical mobility as in (1).

A FE model of a solid panel having dimensions of $0.3 \times 0.2 \mathrm{~m}$ and thickness $1 \mathrm{~mm}$ is developed with simply supported condition along all the edges. The panels are made of aluminium having Young's modulus of $70 \mathrm{GPa}$, density of $2700 \mathrm{~kg} \mathrm{~m}^{-3}$, and Poisson's ratio of 0.3 . The $2 \mathrm{D}$ shell elements are used to model plate structures where a shell structure carries loads in all directions and therefore undergoes bending and twisting, as well as in-plane deformation [11].

The mesh element type used in the FE model is the basic two-dimensional triangular element (Tria shape and Paver). The element size is set to be much smaller than half of the structural wavelength corresponding to the maximum frequency of analysis to give accurate results at high frequencies. The global edge length of each element is set to be $0.003 \mathrm{~m}$ which is sufficient to provide accurate result up to $5 \mathrm{kHz}$. The plate was set to be an ideal simply supported boundary condition, where the displacement is restrained at the plate edges, but the rotation is set to be free. The location of the excitation force and the response are the same for all simulated plates for consistency of plate mobility analysis.

An excitation force of $1 \mathrm{~N}$ is applied slightly away from the centroid of the panel at coordinates $(0.18,0.12)$ where the $(0,0)$ is at the bottom left corner of the plate as illustrated in Figure 1. This is to generate optimum numbers of vibration modes particularly at low frequencies. The damping loss factor is set to be 0.03 which is a typically small value for most engineering structures. The vibration level of the panel is analyzed in the frequency range of $10 \mathrm{~Hz}$ to $5 \mathrm{kHz}$. From the FE calculation, by extracting the vibration velocity from the response point and as a unit force was used, this result gives the mobility. The result is postprocessed using MATLAB. For the theory, the calculation was also performed using MATLAB for 400 modes $(p=20, q=20)$ up to $5 \mathrm{kHz}$ with the same location of excitation force and response as well as the value of the damping factor. The comparison of the results is shown in Figure 2(a) with good agreement particularly below $1 \mathrm{kHz}$. Above $1 \mathrm{kHz}$, small discrepancies 


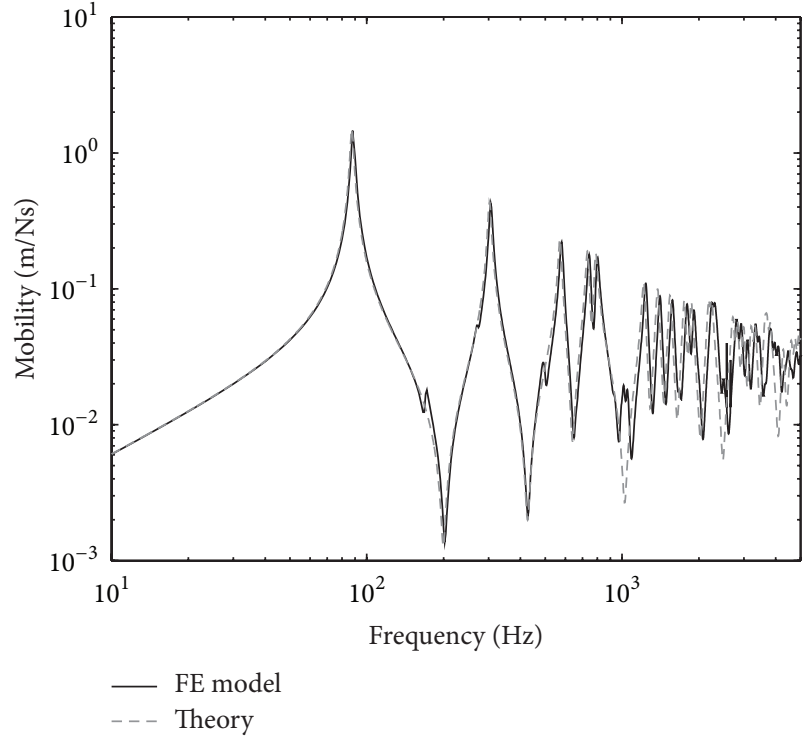

(a)

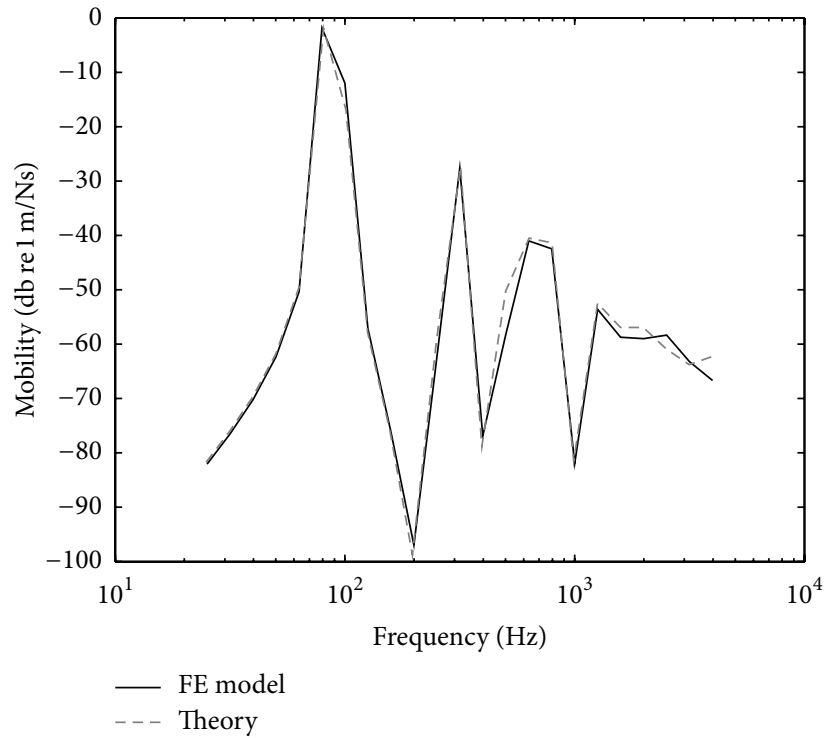

(b)

FIGURE 2: Comparison of mobility of a solid panel from FE model and from analytical calculation: (a) narrow band and (b) one-third octave band.

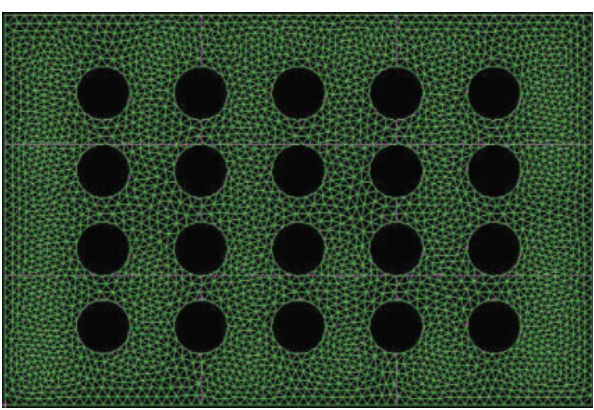

(a)

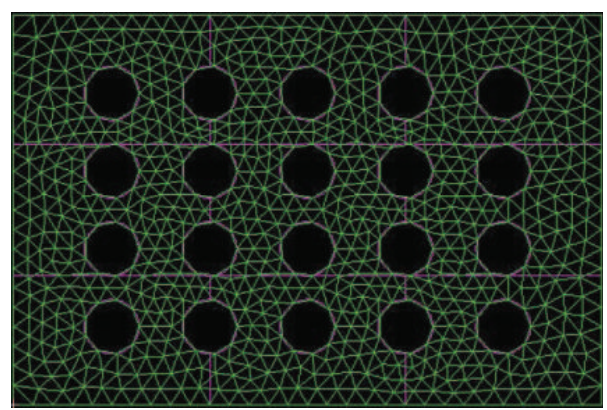

(b)

Figure 3: Examples of the Finite Element model of the perforations with different mesh size represented by the global edge length (GEL): (a) $\mathrm{GEL}=3 \mathrm{~mm}$ and (b) GEL $=10 \mathrm{~mm}$.

can be observed, but the average level is almost the same as seen in one-third octave band frequencies in Figure 2(b).

In order to ensure the right meshing is used in this study, the effect of the size of the mesh is also investigated by simulating the mobility of a perforated panel with different global edge length (GEL) of the mesh. Figure 3 shows two examples of the FE model with different meshing size. Figure 4 plots the mobility for four different GELs. It can be observed that the results for perforated plates with GEL = $3 \mathrm{~mm}$ and $5 \mathrm{~mm}$ have the same results which collapse together for the corresponding frequency range. For larger GEL, that is, GEL $=10 \mathrm{~mm}$ and GEL $=20 \mathrm{~mm}$, the mobility shifts to higher frequency. Thus, for the rest of the simulation, GEL $=5 \mathrm{~mm}$ is used in this study.

2.2.2. FE Model for Perforated Panels. The simulated samples of perforated panels are determined by varying the perforation ratio with fixed diameter or number of holes
TABLE 1: Parameters of the perforated panel with fixed hole diameter and different number of holes and perforation ratio.

\begin{tabular}{lccc}
\hline Name & Number of holes & $\begin{array}{c}\text { Diameter } \\
(\mathrm{mm})\end{array}$ & $\begin{array}{c}\text { Perforation ratio } \\
(\%)\end{array}$ \\
\hline P40-10-5 & 40 & 10 & 5 \\
P80-10-5 & 80 & 10 & 10 \\
P160-10-5 & 160 & 10 & 21 \\
\hline
\end{tabular}

and also by varying the diameter and number of holes with fixed perforation ratio. For comprehensive study, this also includes the arrangement of holes in the plate, which can be a triangular pattern (usually referred to as diagonal pattern) or a square array as well as the hole distributions in the plate, that is, those concentrated on the middle or along the plate edges. The choice of these parameters is summarized in Tables 1, 2, 3, 4, and 5. For convenience of referring of 


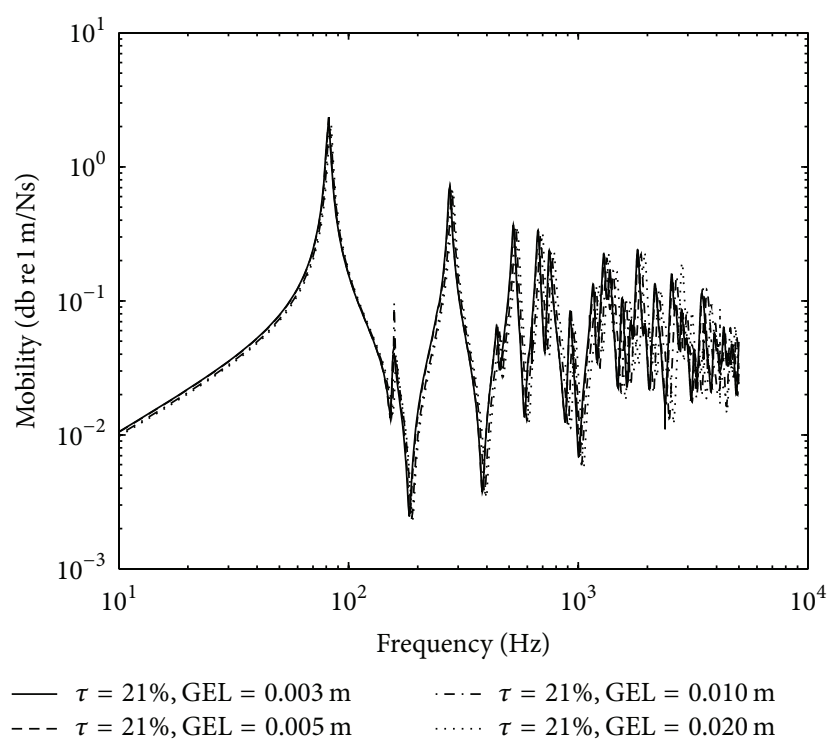

FIGURE 4: Mobility of a solid plate with different global edge length of the mesh.

TABle 2: Parameters of the perforated panel with different hole diameter and number of holes and fixed perforation ratios.

\begin{tabular}{lccc}
\hline Name & Number of holes & $\begin{array}{c}\text { Diameter } \\
(\mathrm{mm})\end{array}$ & $\begin{array}{c}\text { Perforation ratio } \\
(\%)\end{array}$ \\
\hline P20-20-10 & 20 & 20 & 10 \\
P40-14-10 & 40 & 14 & 10 \\
P80-10-10 & 80 & 10 & 10 \\
P20-28-21 & 20 & 28 & 21 \\
P30-23-21 & 30 & 23 & 21 \\
P40-20-21 & 40 & 20 & 21 \\
P20-34-30 & 20 & 20 & 30 \\
P30-28-30 & 30 & 34 & 30 \\
P58-20-30 & 58 & 28 & 30 \\
\hline
\end{tabular}

TABle 3: Parameters of the perforated panel with fixed number of holes and different hole diameter and perforation ratio.

\begin{tabular}{lccc}
\hline Name & Number of holes & $\begin{array}{c}\text { Diameter } \\
(\mathrm{mm})\end{array}$ & $\begin{array}{c}\text { Perforation ratio } \\
(\%)\end{array}$ \\
\hline P40-10-5 & 40 & 10 & 5 \\
P40-14-10 & 40 & 14 & 10 \\
P40-15-12 & 40 & 15 & 12 \\
P40-20-21 & 40 & 20 & 21 \\
\hline
\end{tabular}

the plate, each perforated plate is named according to its parameter, where the first part of the numbers indicates the number of holes, the second part is the diameter, and the third part is the perforation ratio. The plate parameters are chosen to represent any possibilities of perforation configuration in practice. Figure 5 shows examples of the Finite Element (FE)
TABle 4: Parameters of the perforated panel with different hole distributions.

\begin{tabular}{lccc}
\hline Name & $\begin{array}{c}\text { Number of } \\
\text { holes }\end{array}$ & $\begin{array}{c}\text { Diameter } \\
(\mathrm{mm})\end{array}$ & $\begin{array}{c}\text { Perforation ratio } \\
(\%)\end{array}$ \\
\hline P40-14-10 & 40 & 14 & 10 \\
P40-14-10-edge & 40 & 14 & 10 \\
P40-14-10-center & 40 & 14 & 10 \\
P20-28-21 & 20 & 28 & 21 \\
P20-28-21-edge & 20 & 28 & 21 \\
P20-28-21-center & 20 & 28 & 21 \\
\hline
\end{tabular}

TABle 5: Parameters of the perforated panel with different hole arrays.

\begin{tabular}{lccc}
\hline Name & $\begin{array}{c}\text { Number of } \\
\text { holes }\end{array}$ & $\begin{array}{c}\text { Diameter } \\
(\mathrm{mm})\end{array}$ & $\begin{array}{c}\text { Perforation ratio } \\
(\%)\end{array}$ \\
\hline P40-14-10 & 40 & 14 & 10 \\
P41-14-10-tria & 40 & 14 & 10 \\
P40-20-21 & 40 & 20 & 21 \\
P41-20-21-tria & 40 & 20 & 21 \\
\hline
\end{tabular}

model of perforated panels from PATRAN software with the mesh condition as described in Section 2.2.1.

2.2.3. Validation with Experiment. A modal test is carried out to validate the FE result. The experimental setup for measuring the mobility is shown in Figure 6. To realise the free-free boundary conditions, the plate was hung vertically using light-rope. At the same location where the Kistler instrumented hammer stroked, a DYTRAN "teardrop" accelerometer was attached to the plate to measure 


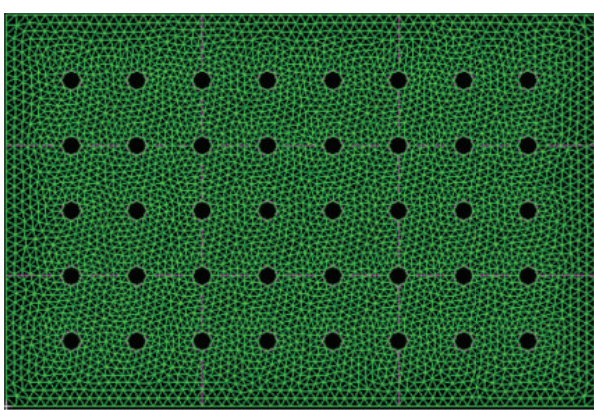

(a)

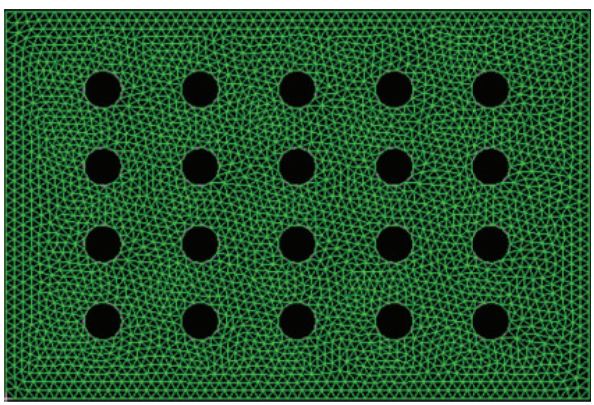

(c)

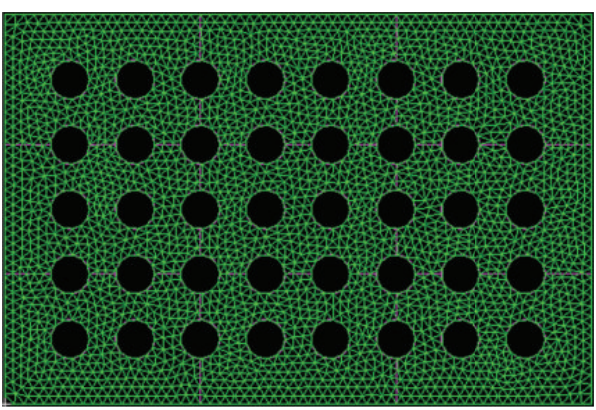

(e)

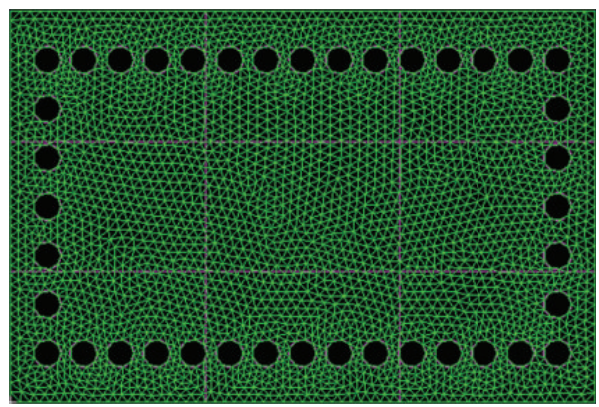

(g)

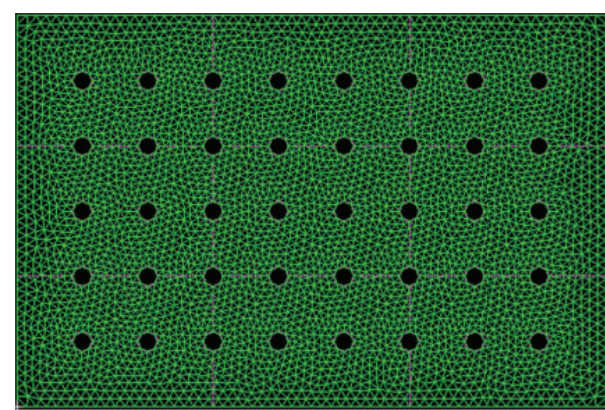

(b)

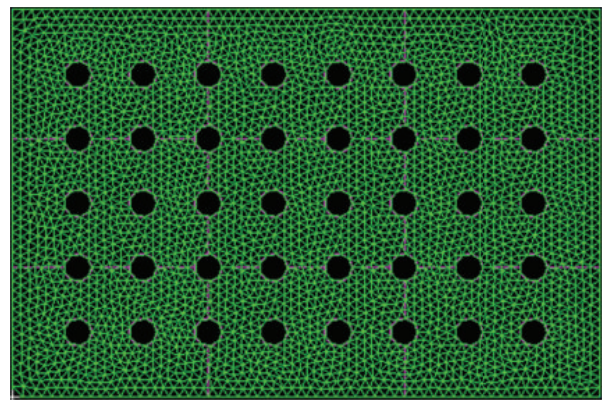

(d)

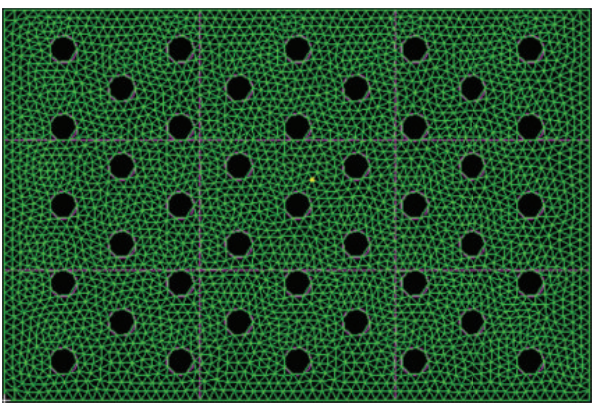

(f)

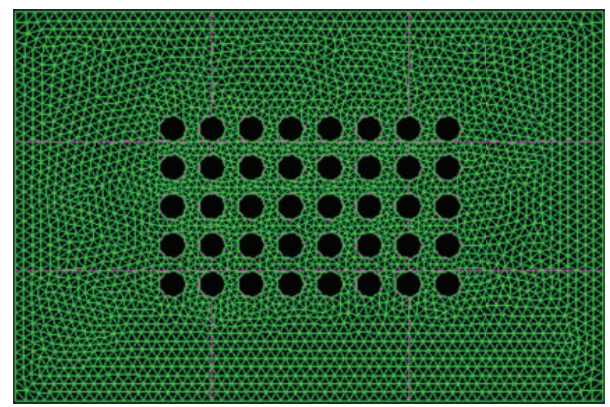

(h)

Figure 5: Examples of the Finite Element model of the perforations. Fixed hole diameter: (a) P40-10-5 and (b) P80-10-10; fixed perforation ratio: (c) P20-20-10 and (d) P40-14-10; different hole arrangement: (e) P40-20-21 and (f) P41-20-21; different hole distribution: (g) P40-14-10edge and (h) P40-14-10-center.

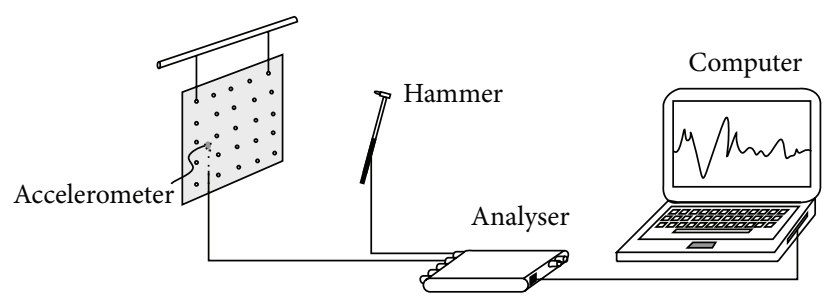

FIGURE 6: Experimental setup for mobility measurement using impact hammer. 


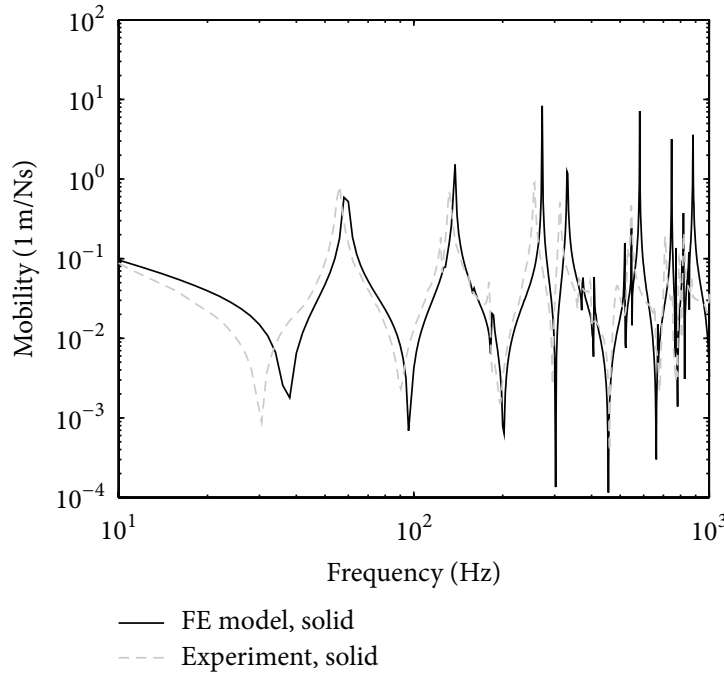

(a)

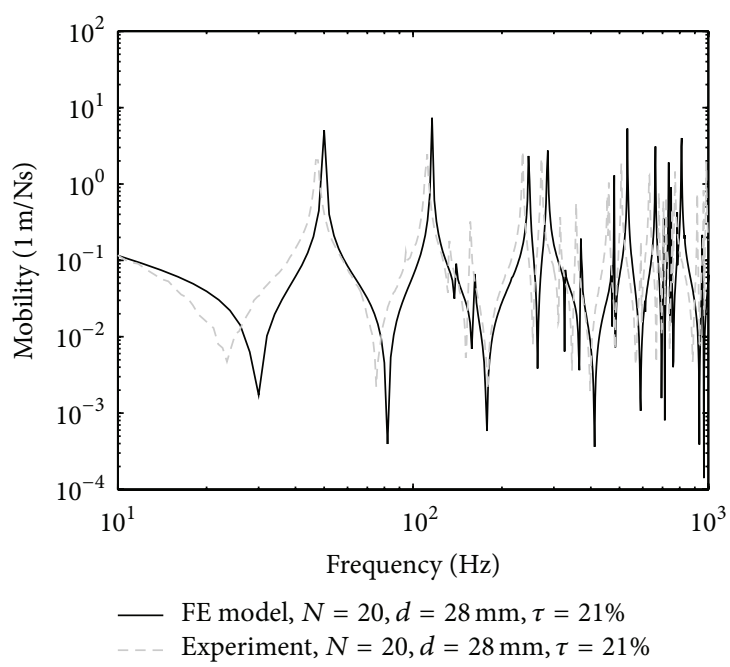

(c)

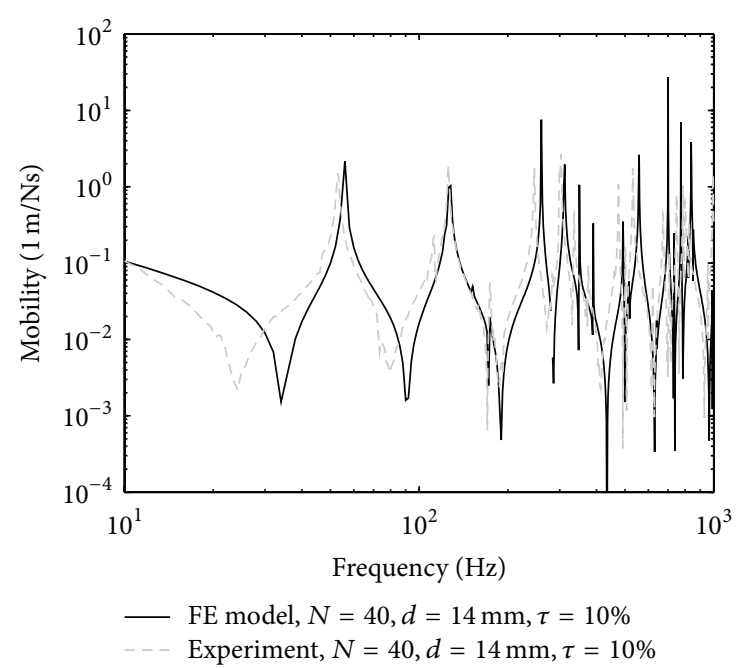

(b)

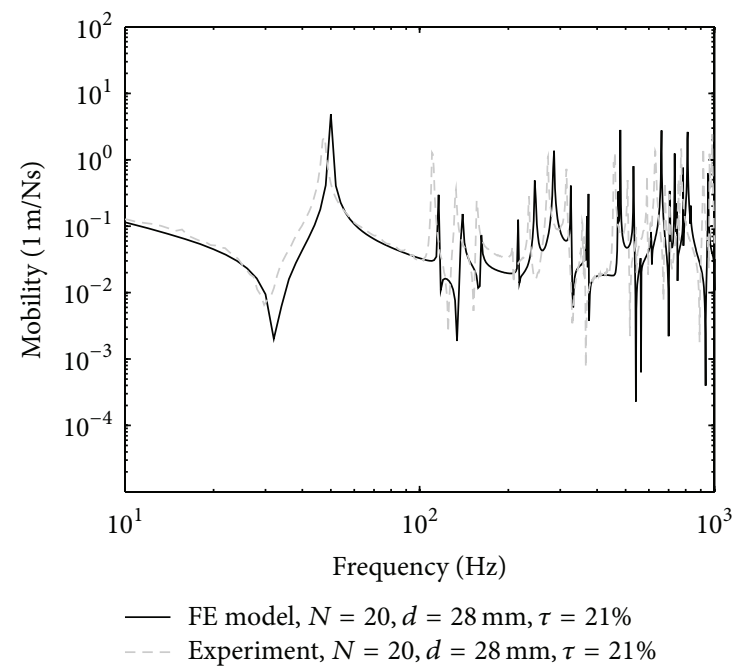

(d)

FIGURE 7: Comparison of the mobility for solid and perforated panels from FE model and experiment: (a) solid and (b)-(c) perforated panels at different perforation ratio. (d) Transfer mobility for fixed perforation ratio of $20 \%$.

the plate acceleration. The signal was recorded and processed using Data Physics signal analyzer. Figure 7 shows the results from the FE models and the experiment where satisfactory agreement is achieved. Small discrepancies occur which might be due to the nonuniformity of the panel in the experiment which is different from the ideal plate defined in the FE model.

\section{Simulation Results and Discussion}

The numerical results from the FE model are presented in one-third octave bands to observe the "average" level of mobility in a frequency band rather than to deal with details of discrepancies in the narrow band. Also for convenience of analysis, it is of interest to observe the amount of mobility level which increases due to perforation. This can be expressed with "the effect of perforation" in $\mathrm{dB}$ unit by

$$
X=20 \times \log _{10}\left(\frac{Y_{p}}{Y_{s}}\right),
$$

where $Y_{p}$ is the mobility of the perforated plate and $Y_{s}$ is for the solid plate. The results are presented for both mobility $Y$ and effect of perforation $X$ positioned side-by-side.

\subsection{Effect of Hole Diameter and Number of Holes at Fixed} Perforation Ratio. In Figure 8, it is shown that, by comparing the solid and the perforated plates, introduction of perforation increases the mobility from low to high frequency. 


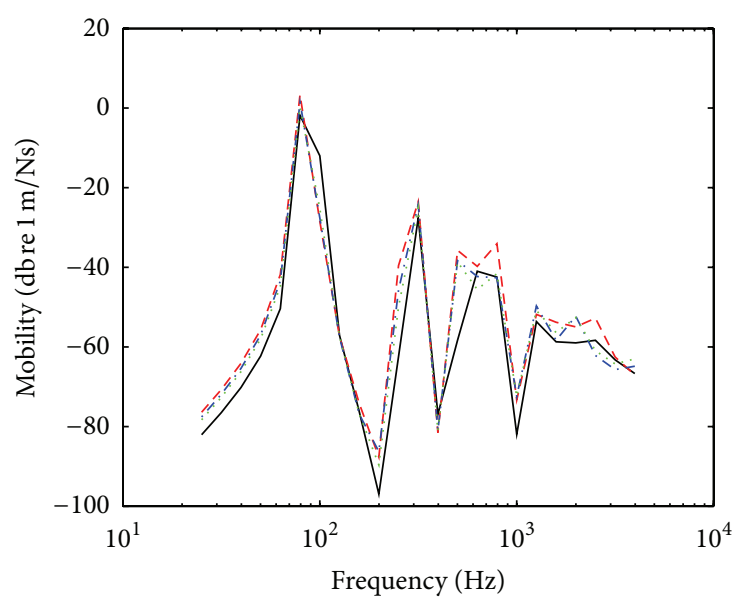

$\begin{array}{lll}- \text { Solid plate } & \cdots-N=40, d=14 \mathrm{~mm}, \tau=10 \% \\ --N=20, d=20 \mathrm{~mm}, \tau=10 \% & \cdots & N=80, d=10 \mathrm{~mm}, \tau=10 \%\end{array}$

(a)

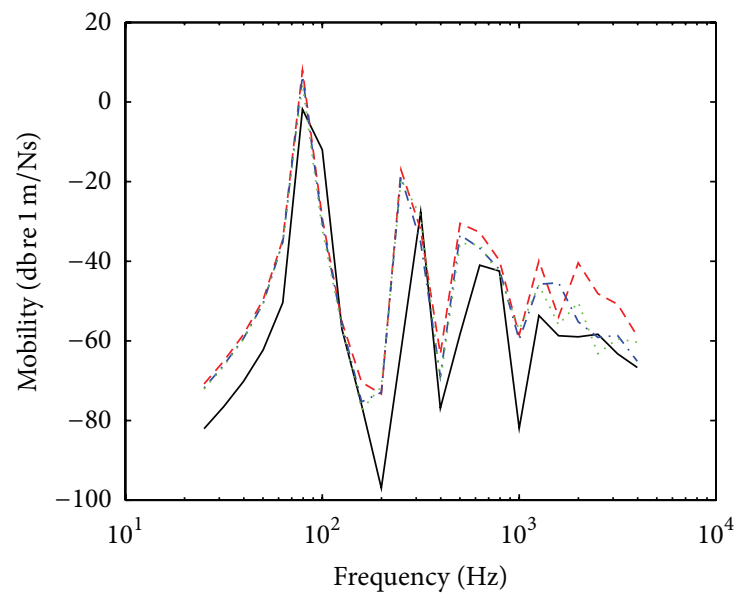

$\begin{array}{ll}\text { Solid plate } & \cdots N=30, d=23 \mathrm{~mm}, \tau=21 \% \\ --N=20, d=28 \mathrm{~mm}, \tau=21 \% & \cdots N \quad N=40, d=20 \mathrm{~mm}, \tau=21 \%\end{array}$

(c)

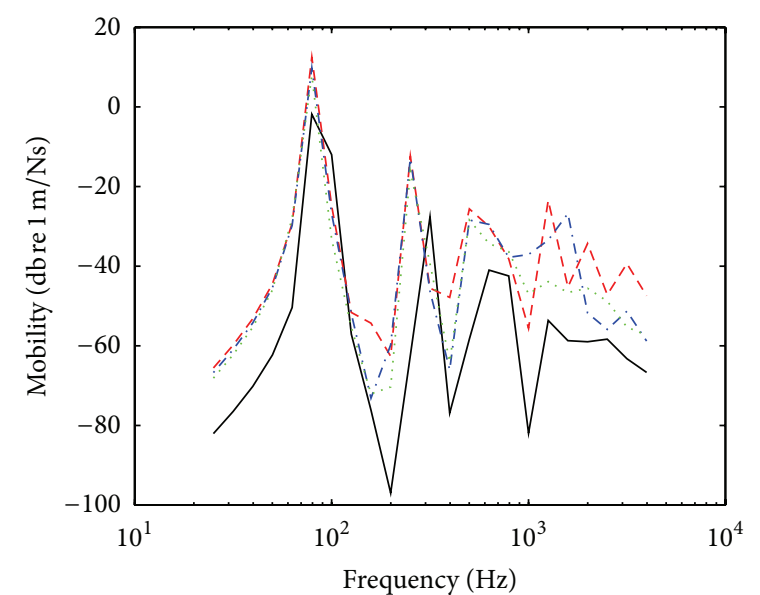

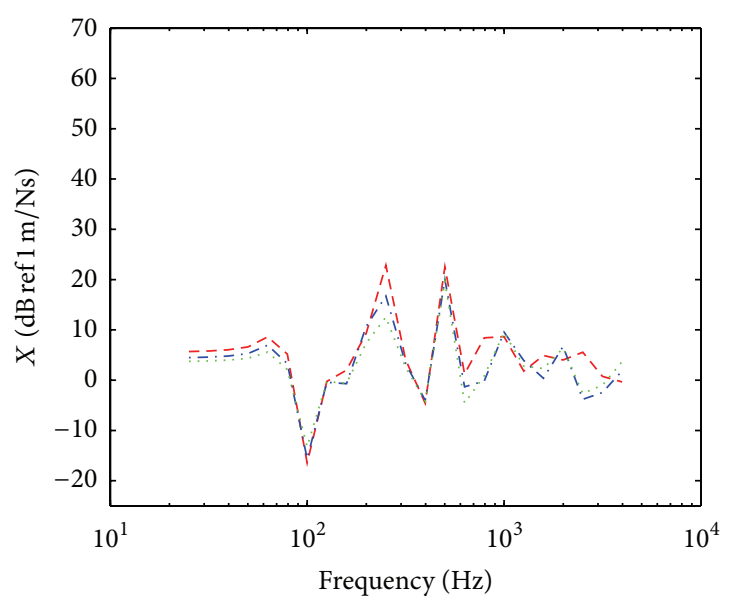

- - $N=20, d=20 \mathrm{~mm}, \tau=10 \% \quad \cdots \quad N=80, d=10 \mathrm{~mm}, \tau=10 \%$ -.. $N=40, d=14 \mathrm{~mm}, \tau=10 \%$

(b)

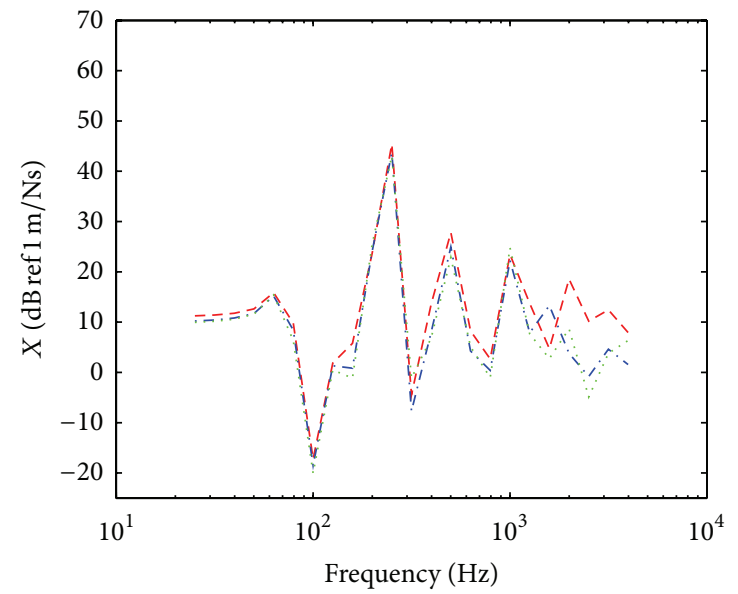

- - $N=20, d=28 \mathrm{~mm}, \tau=21 \% \cdots \cdots \quad N=40, d=20 \mathrm{~mm}, \tau=21 \%$ . - - $N=30, d=23 \mathrm{~mm}, \tau=21 \%$

(d)

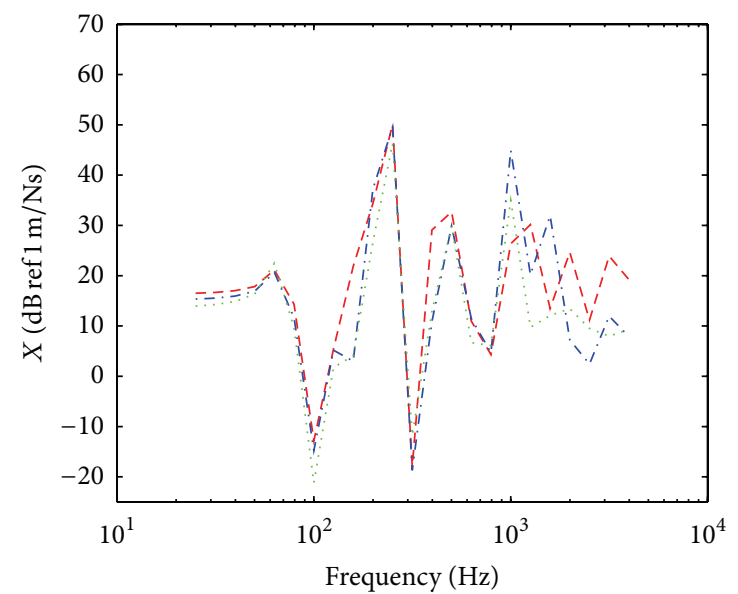

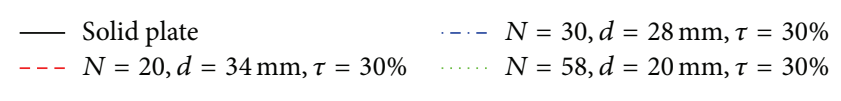

(e)

$$
\begin{aligned}
&--N=20, d=34 \mathrm{~mm}, \tau=30 \% \ldots \ldots N=58, d=20 \mathrm{~mm}, \tau=30 \% \\
& \cdots-N=30, d=28 \mathrm{~mm}, \tau=30 \%
\end{aligned}
$$

(f)

Figure 8: Mobility ((a), (c), and (e)) and effect of perforation ((b), (d), (f)) of the perforated panels with different hole diameters and number of holes at fixed perforation ratio. 


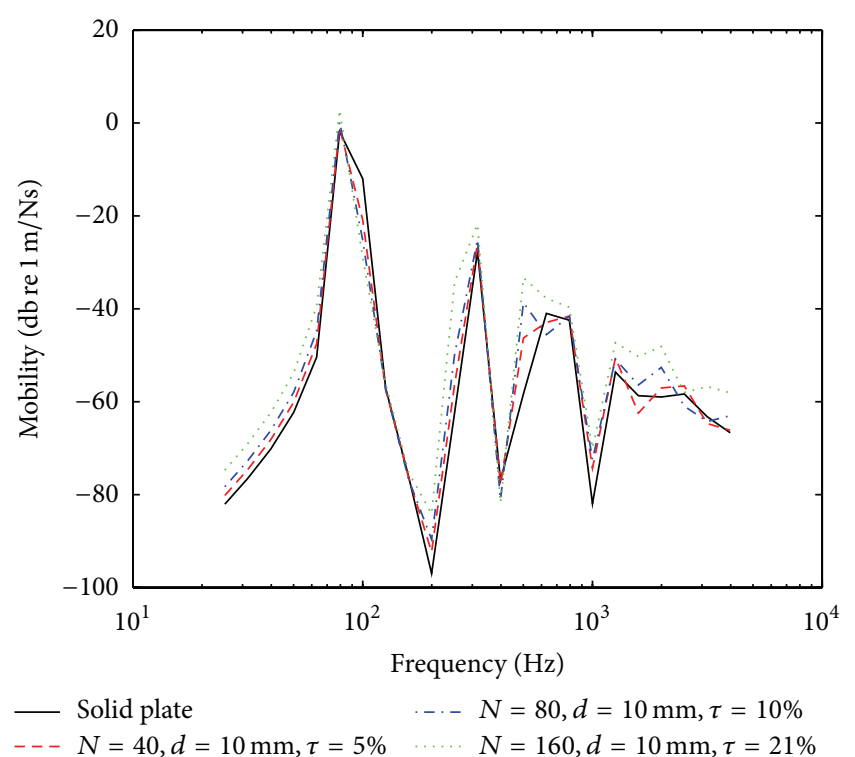

(a)

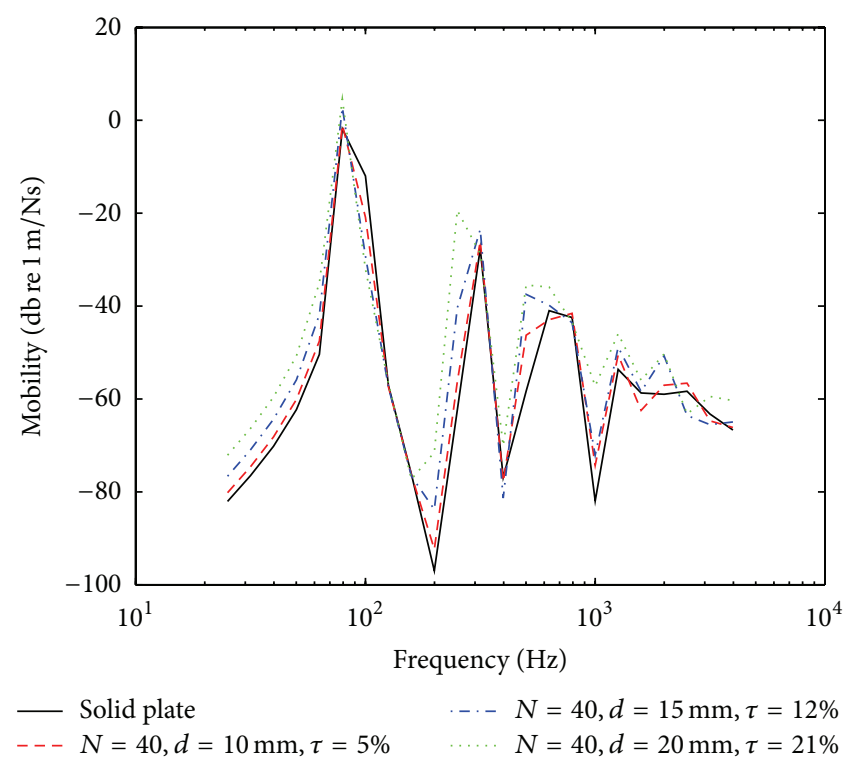

(c)

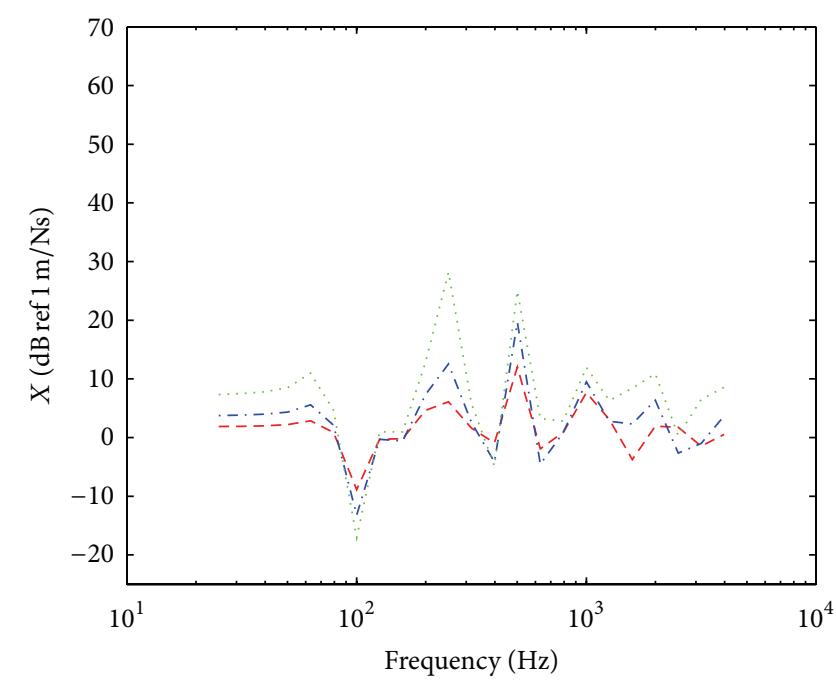

$\begin{aligned} &--N=40, d=10 \mathrm{~mm}, \tau=5 \% \cdots \cdots N=160, d=10 \mathrm{~mm}, \tau=21 \% \\ & \cdots-N=80, d=10 \mathrm{~mm}, \tau=10 \%\end{aligned}$

(b)

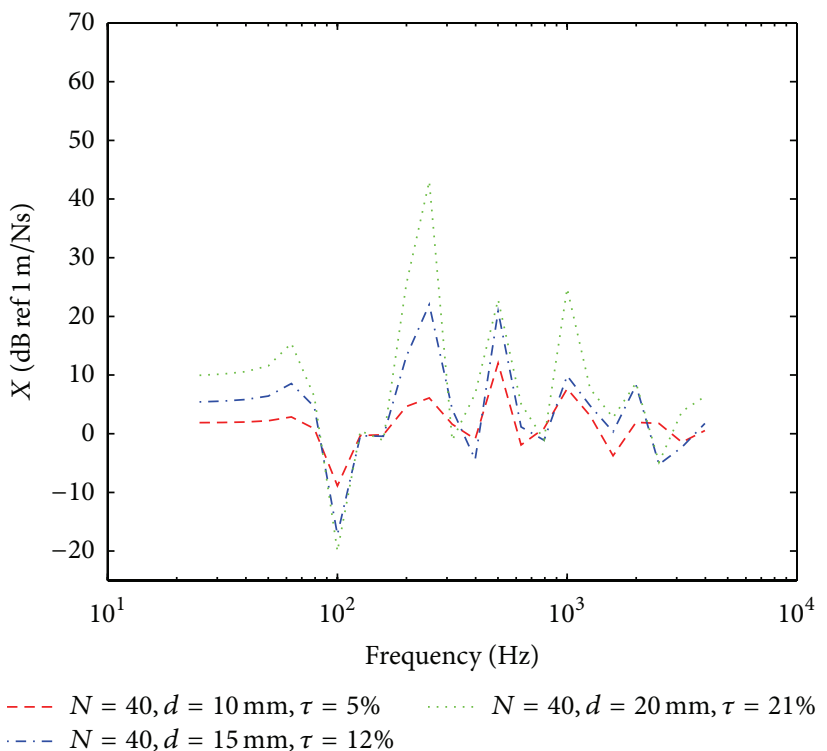

(d)

Figure 9: Mobility ((a), (c)) and effect of perforation ((b), (d)) of the perforated panels with fixed hole diameter and fixed number of holes.

The level of increment becomes greater as the perforation ratio increases. However, among the perforated plates with fixed perforation ratio, varying the hole diameter as well as the number of holes does not have significant change on the mobility except at high frequencies (above $1 \mathrm{kHz}$ ). This can also be seen in the effect of perforation $X$ results. The variation of mobility for different hole diameters (with fixed perforation ratio) can be clearly observed as the perforation ratio is increased. The largest hole diameter gives the highest mobility at high frequencies. This indicates that, at high frequencies, the mobility of the perforations depends on the hole density in the panel where large hole density (many holes, but smaller) is preferred to reduce vibration. Larger hole density has also been shown to produce the greatest noise reduction effect [1,2].

It should be noted here that the high peaks shown in the effect of perforation at low frequencies below $1 \mathrm{kHz}$, for example, at the fundamental frequency of the plate, that is, $250 \mathrm{~Hz}$, are the effects due to the natural frequency shift because of perforation [7], although the level at the fundamental frequency as seen in Figure 8(e) is also increased by roughly $10 \mathrm{~dB}$ compared to the level at the fundamental frequency of the solid plate.

3.2. Effect of Perforation Ratio at Fixed Hole Diameter or Fixed Number of Holes. The effect of increasing the perforation 


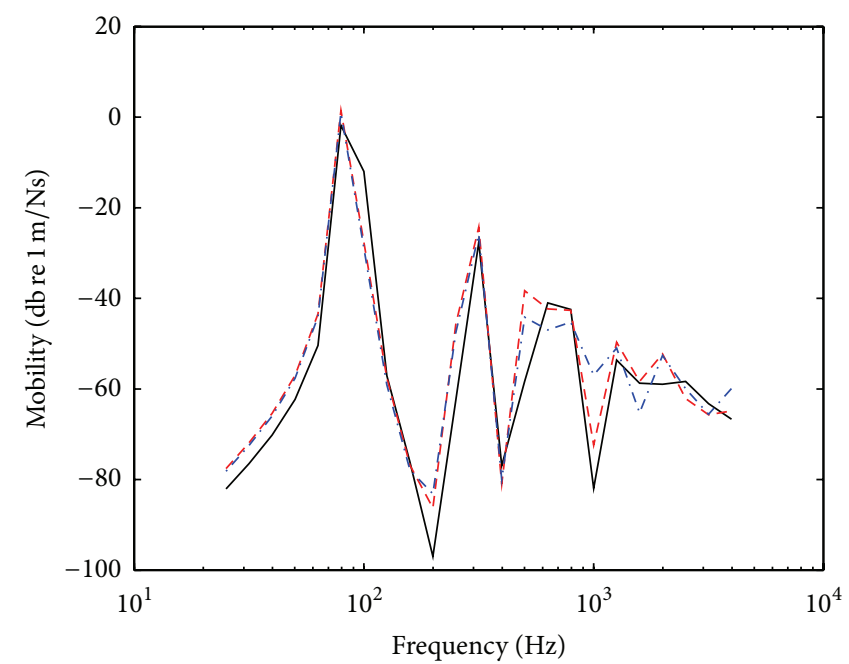

- - - Square, $N=40, d=14 \mathrm{~mm}, \tau=10 \%$

...- Triangular, $N=41, d=14 \mathrm{~mm}, \tau=10 \%$

(a)

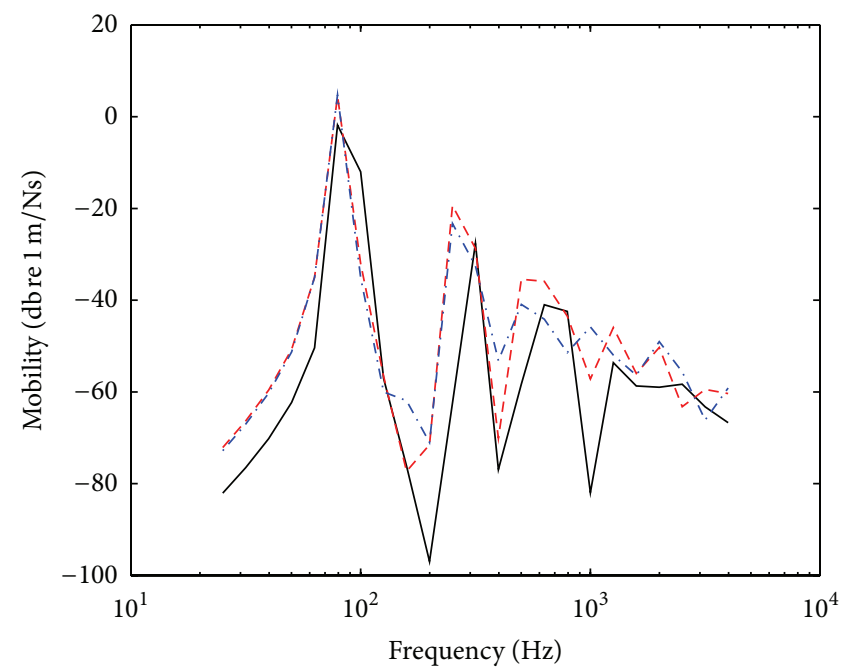

- Solid plate

- - - Square, $N=40, d=20 \mathrm{~mm}, \tau=21 \%$

- .. Triangular, $N=41, d=20 \mathrm{~mm}, \tau=21 \%$

(c)

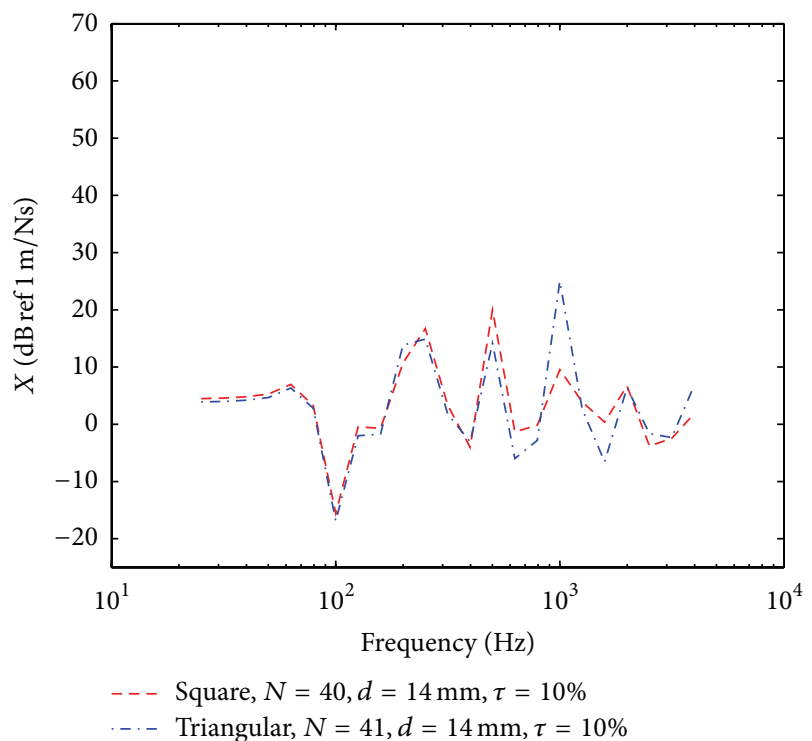

(b)

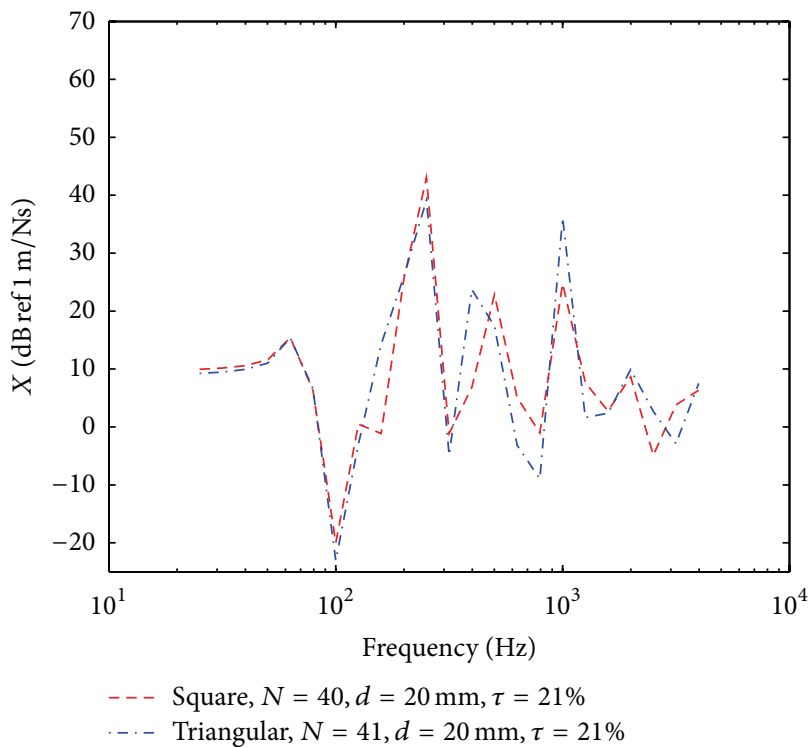

(d)

Figure 10: Mobility ((a), (c)) and effect of perforation ((b), (d)) of the perforated panels with different hole arrays and at fixed perforation ratio.

ratio, by maintaining the hole diameter and by increasing the number of holes, is plotted in Figure 9 where, as already discussed, the mobility increases as the perforation ratio increases. Figure 9 (b) shows that, for $20 \%$ perforation ratio, the mobility can increase to almost $10 \mathrm{~dB}$.

3.3. Effect of Hole Arrays at Fixed Perforation Ratio. For different perforation arrays, that is, square and triangular, at fixed perforation ratio in Figure 10, both perforation arrays also show less significant effect on the plate mobility with each other. The mobility again increases as the perforation ratio is increased (cf. Figures 10(b) and 10(d)). This again confirms that it is the number of holes per unit area (hole density) which affects the plate mobility, not the hole arrays.

3.4. Effect of Holes Arrangement at Fixed Perforation Ratio. For different arrangement of holes, that is, uniform across the plate surface, at the edges of the plate and at the center of plate, the result gives different mobility level for fixed perforation. Figure 11 shows that the panel with centralized arrangement of holes shows the highest increment of mobility level, followed by the uniformly distributed holes across the 


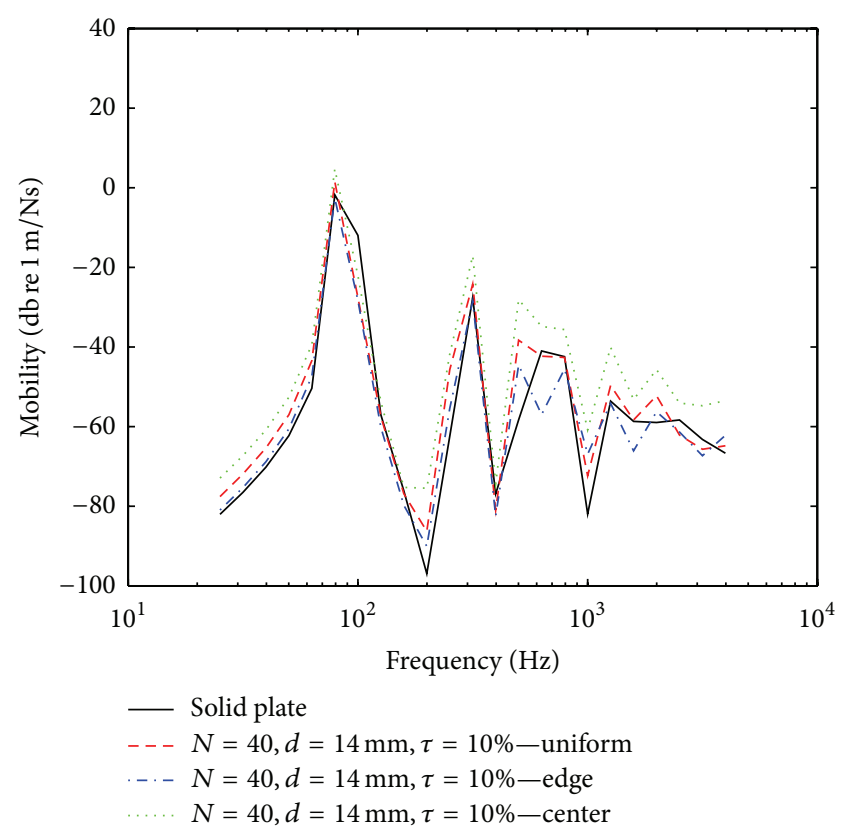

(a)

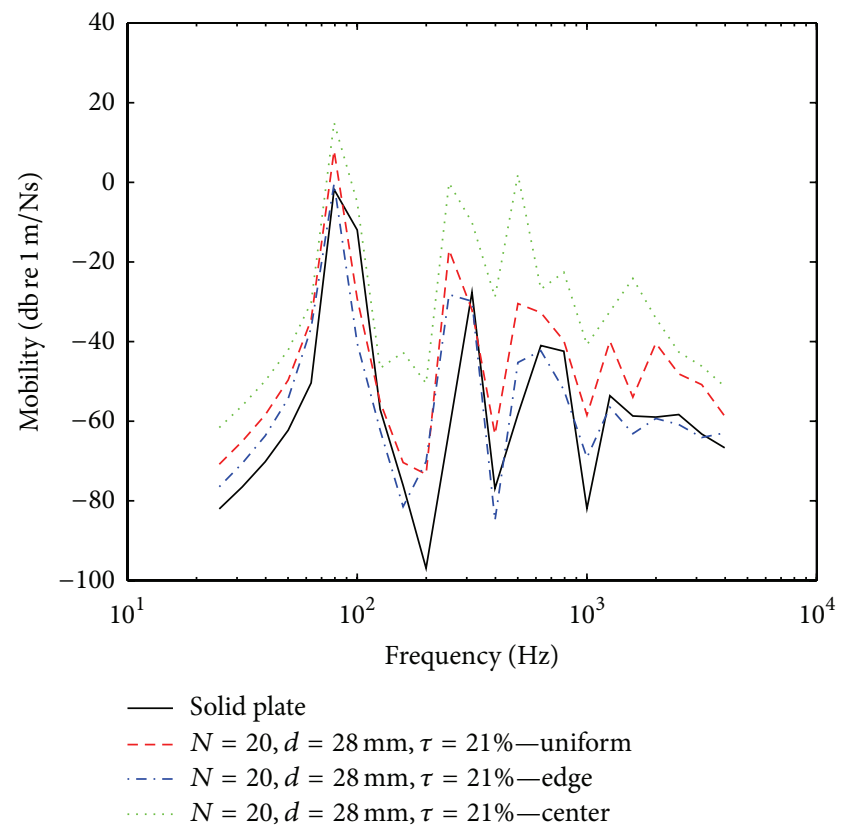

(c)

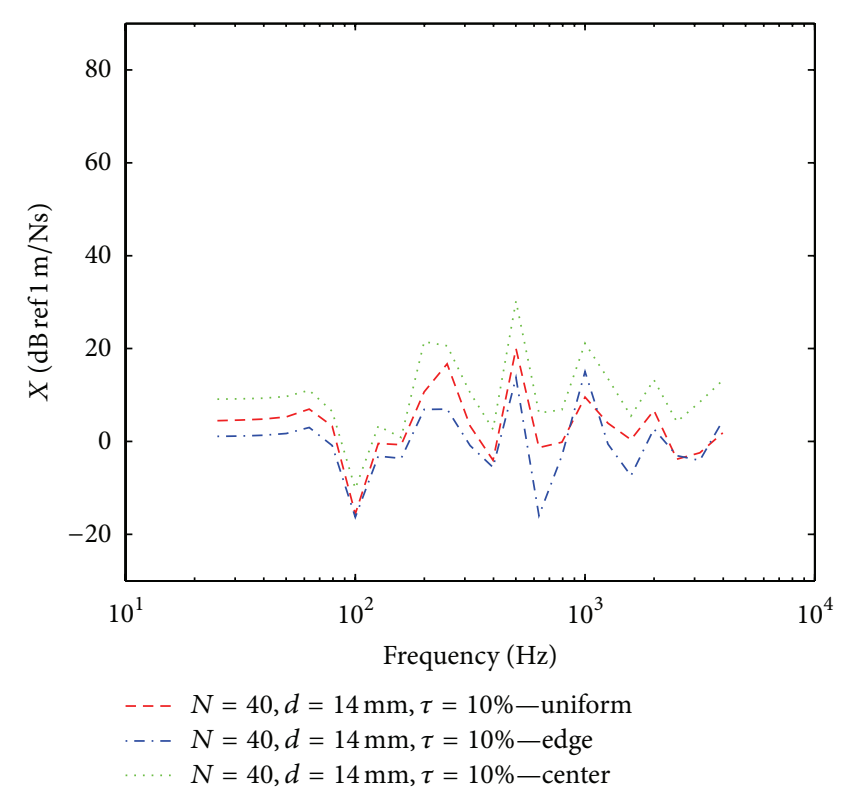

(b)

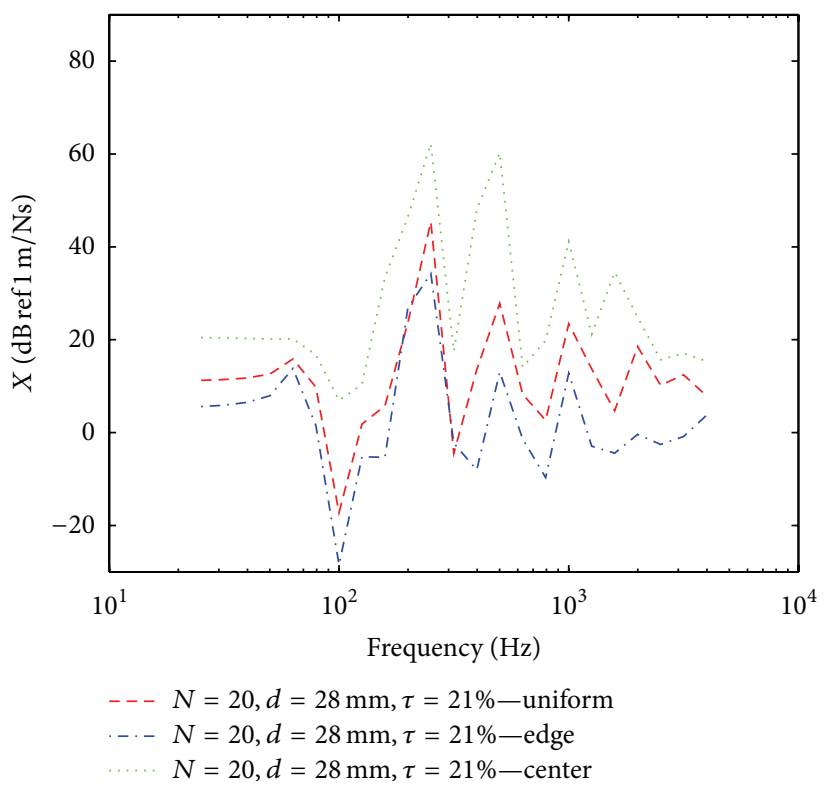

(d)

FIGURE 11: Mobility ((a), (c)) and effect of perforation ((b), (d)) of the perforated panels with different hole arrangement.

plate and the holes at the edges of the plate. The holes at the plate edges can be a useful design for a noise control measure where noise can be reduced at a particular frequency range, that is, at the edge mode region [12].

The mobility can be significantly increased for higher perforation ratio for the centralized holes which can obviously be seen in the effect of perforation $X$ in Figures 11(b) and 11(d). The stiffness of the plate reduces significantly when the concentration of the holes is moved towards the center of the panel, but no effect is obvious from the mobility result when the holes are spread away from the center and concentrated to the plate edges.

3.5. Effect of Boundary Condition. It is also interesting to observe the effect of the boundary conditions to ensure the generality of the conclusion drawn from the study. Another two sets of perforated panels from FE models with free-free and clamped-clamped boundary conditions are developed 


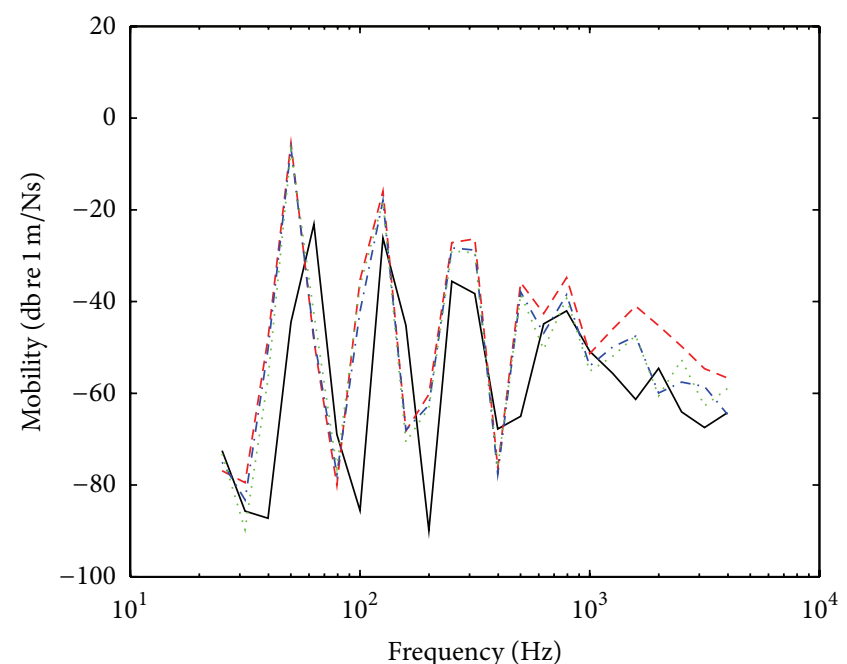

$\begin{array}{ll}\text { - Solid plate } & \cdots N=30, d=23 \mathrm{~mm}, \tau=21 \% \\ --N=20, d=28 \mathrm{~mm}, \tau=21 \% \quad \ldots . . N=40, d=20 \mathrm{~mm}, \tau=21 \%\end{array}$

(a)

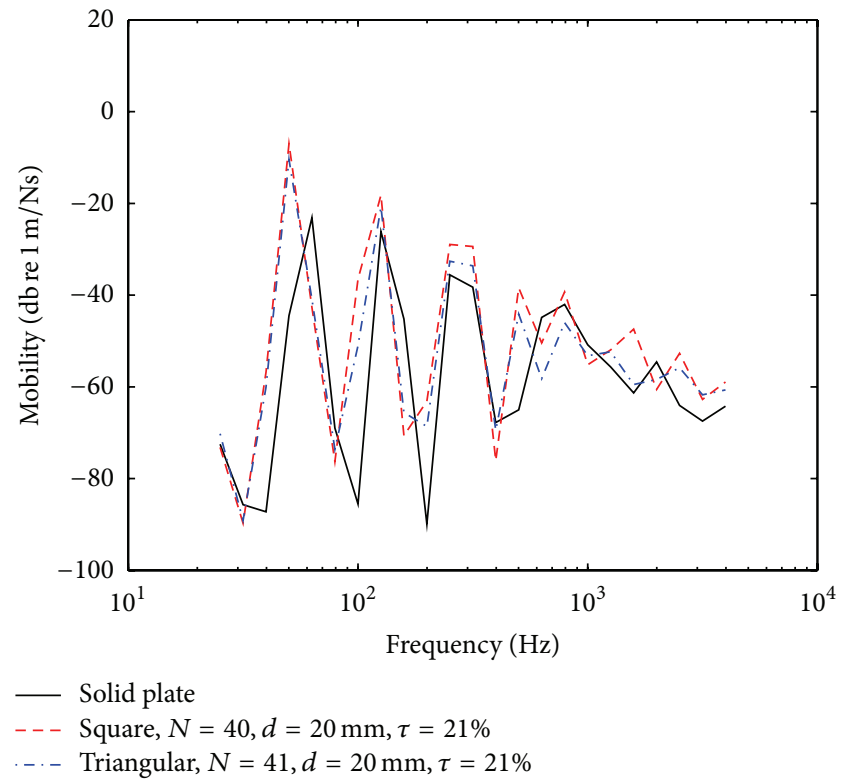

(c)

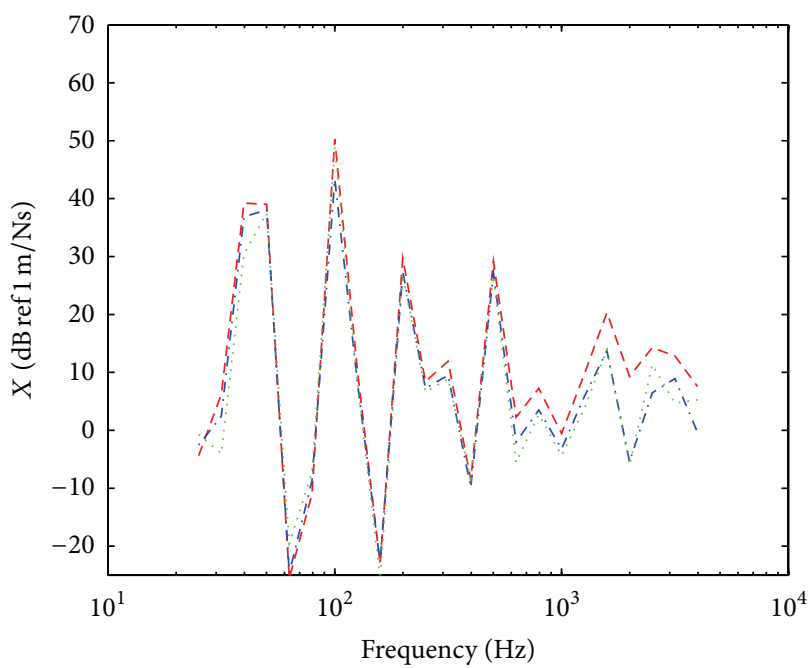

- - $N=20, d=28 \mathrm{~mm}, \tau=21 \% \quad \cdots \cdots, N=40, d=20 \mathrm{~mm}, \tau=21 \%$

-. $-N=30, d=23 \mathrm{~mm}, \tau=21 \%$

(b)

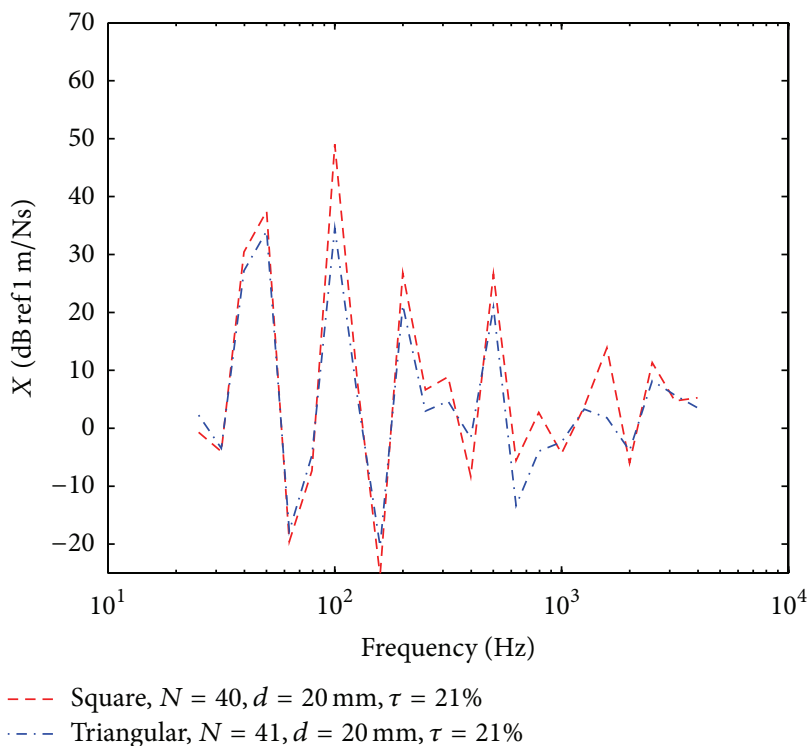

(d)

Figure 12: Mobility ((a), (c)) and effect of perforation ((b), (d)) of the perforated panels for free-free edges for (a)-(b) fixed perforation ratio and (c)-(d) different arrays of holes at fixed perforation ratio.

to investigate the effect of the boundary conditions on the mobility of the perforated panels. For the former, in the FE model, the displacement (vertical, $z$-direction; see again Figure 1) and the rotation at the plate edges are allowed and, for the latter, both the displacement and rotation are constrained. These represent two extreme conditions: the plate with completely free edges and that with completely restrained edges.

The results are shown in Figures 12, 13, 14, and 15 where all the results have the same trend as those from the plate with simply supported boundary condition; that is, the mobility increases when the perforation ratio increases, when the plate has smaller hole density, and when the holes are concentrated at the center of the plate.

3.6. Effect of Response Location. The previous results are calculated for the response point (and excitation location) at a fixed location and therefore the effect of where the holes become closer to the response location is implicit in the results. Here, the effect of the response location at the vicinity of hole is discussed. In Figure 16, it can be seen that the change of mobility is obvious for small perforation ratio where the 


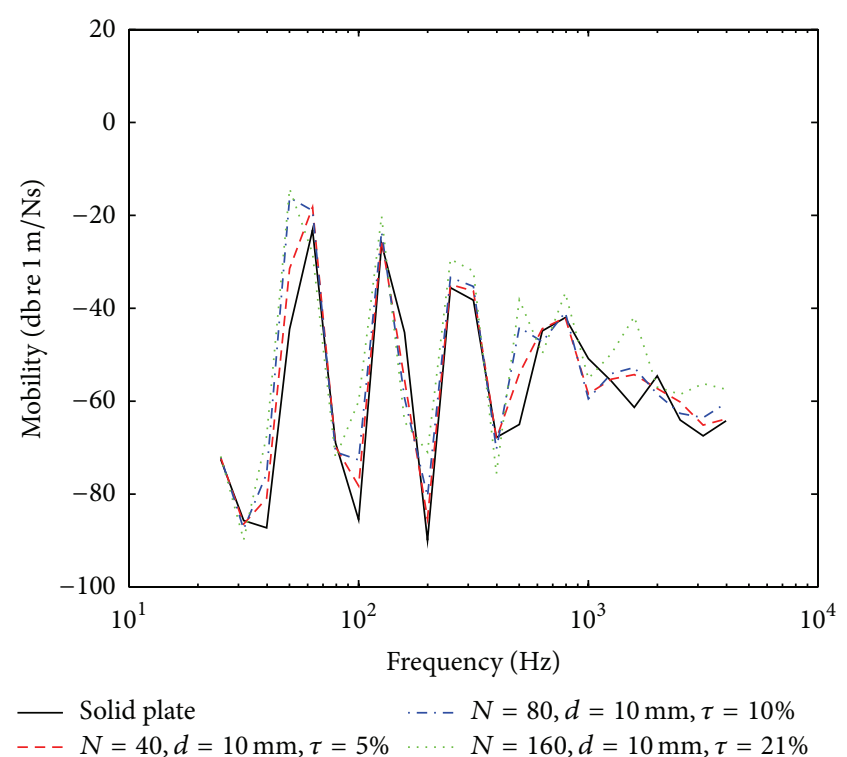

(a)

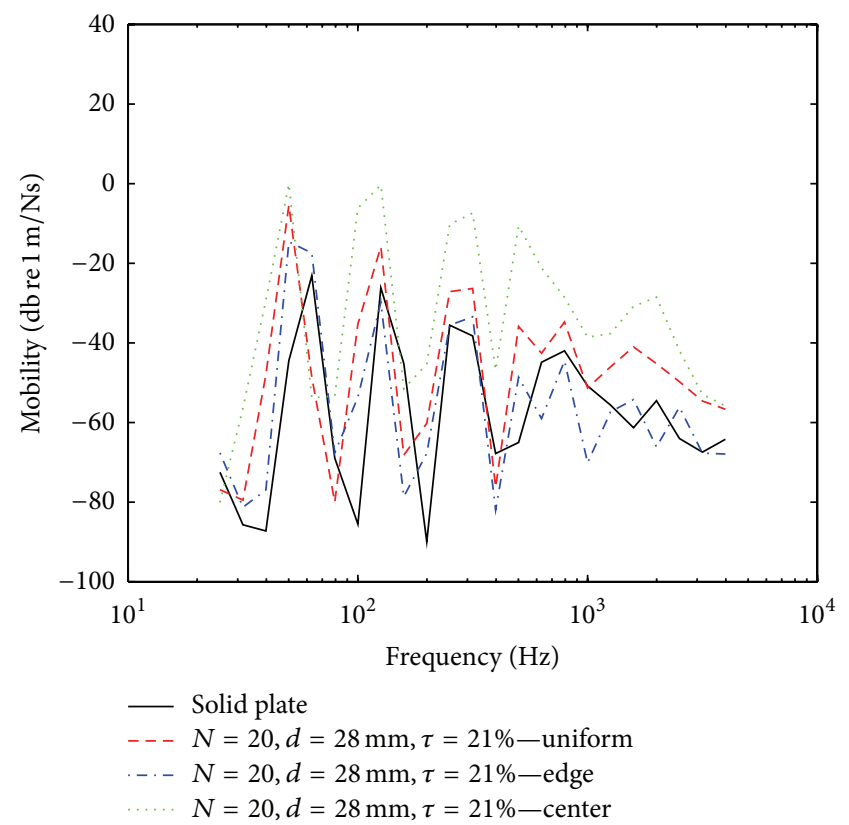

(c)

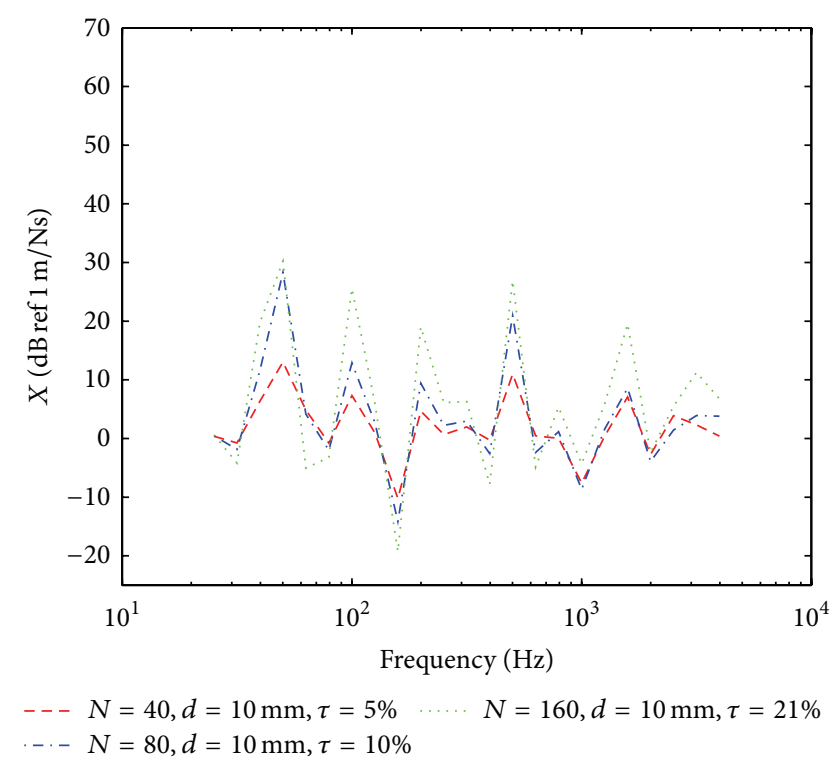

(b)

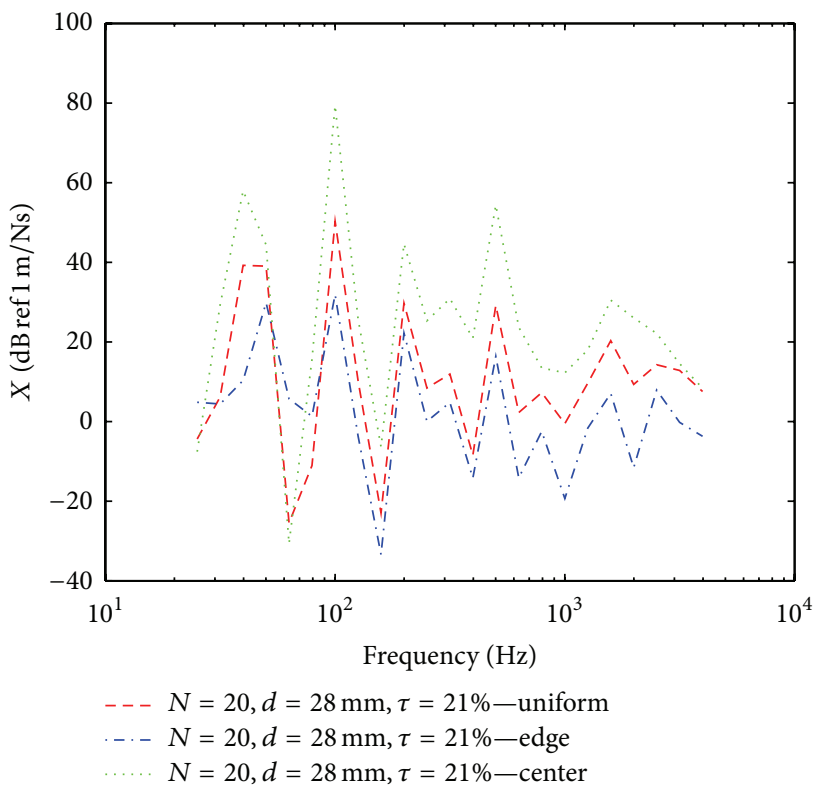

(d)

Figure 13: Mobility ((a), (c)) and effect of perforation ((b), (d)) of the perforated panels for free-free edges for (a)-(b) fixed hole diameter with increasing perforation ratio and (c)-(d) different arrangement of holes at fixed perforation ratio.

separation between holes is large (Figures 16(a) and 16(b)). This is because the local stiffness around the hole is lower compared to the one away from the hole and thus increases the mobility. As the hole separation becomes smaller, the previous "localized" stiffness reduction now becomes more "global" across the plate. Hence, for larger perforation ratios, the change of the mobility due to the change of the response location is not too obvious as seen in Figures 16(c)-16(d) and $16(\mathrm{e})-16(\mathrm{f})$.
Figure 17 shows the contour of stress distribution calculated from PASTRAN and NASTRAN which can be associated with the phenomena of stiffness reduction. It can be observed that the highest stress level is concentrated only around the excitation point close to the hole for small perforation ratio as seen in Figure 17(a). The concentration of the stress distributes to more holes as the holes are closer together (high perforation ratio) as in Figure 17(b). As the holes become more closer as shown in Figure 17(c), 


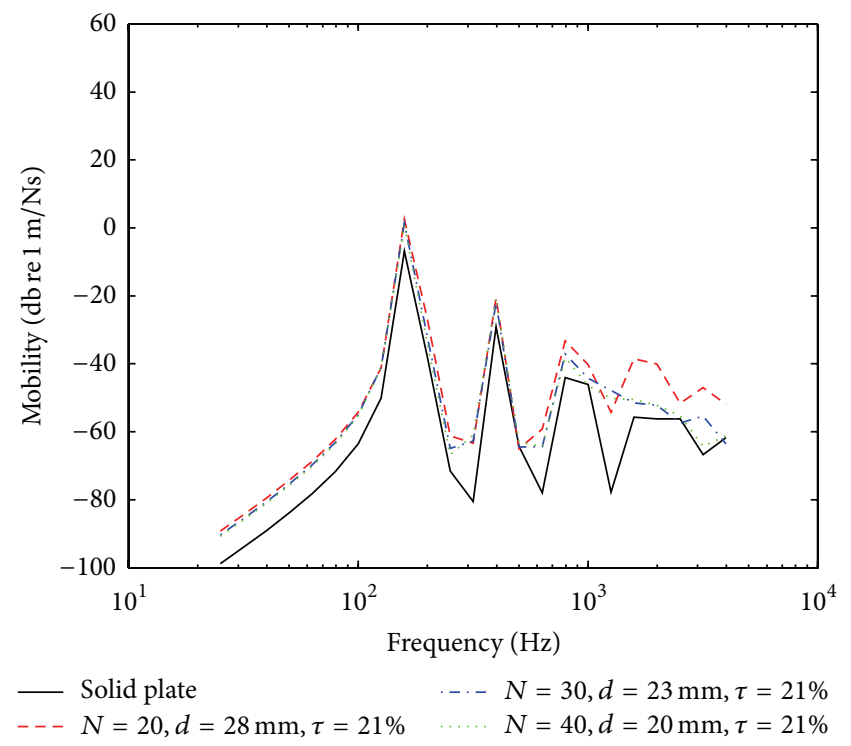

(a)

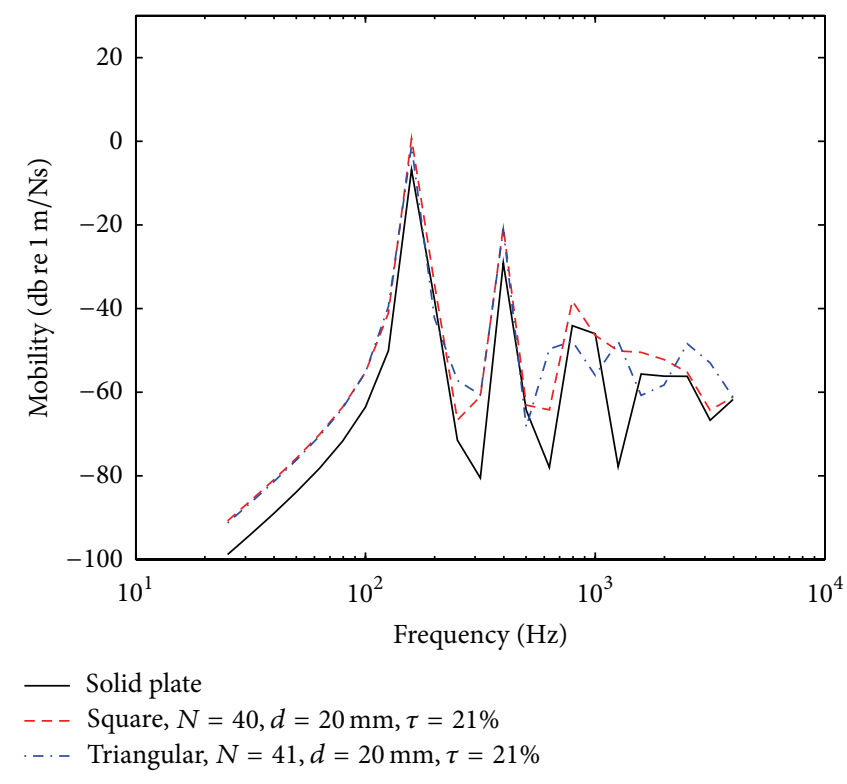

(c)

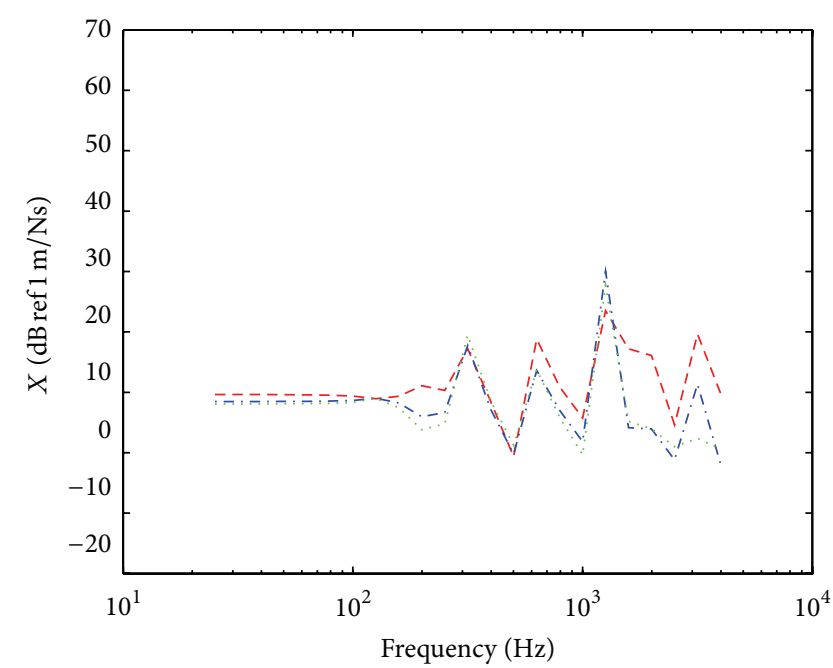

- - $N=20, d=28 \mathrm{~mm}, \tau=21 \% \quad \cdots \quad N=40, d=20 \mathrm{~mm}, \tau=21 \%$

-.. $N=30, d=23 \mathrm{~mm}, \tau=21 \%$

(b)

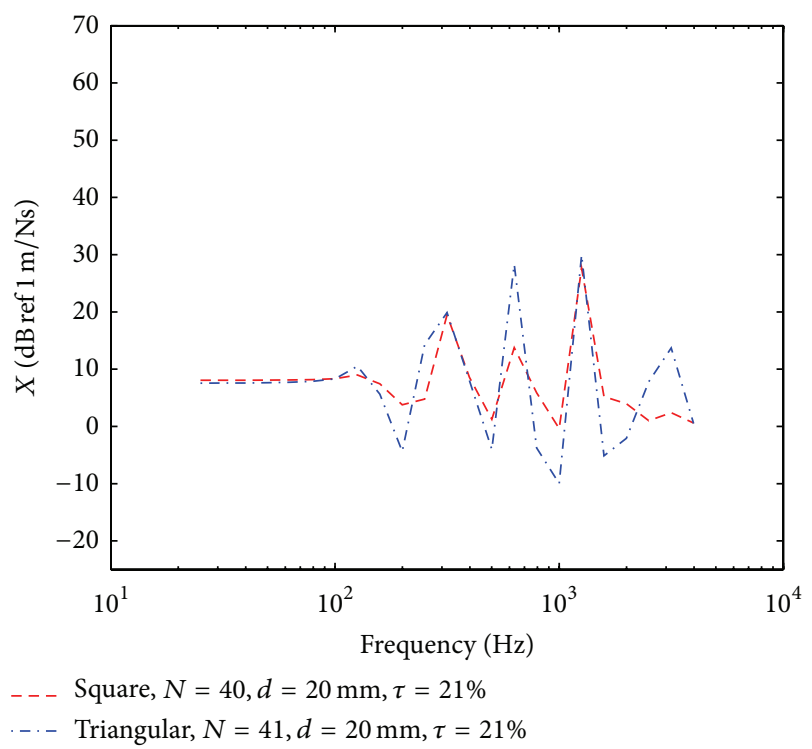

(d)

Figure 14: Mobility ((a), (c)) and effect of perforation ((b), (d)) of the perforated panels for clamped-clamped edges for (a)-(b) fixed perforation ratio and (c)-(d) different arrays of holes at fixed perforation ratio.

the level of stress increases and almost all holes have high concentration of stress.

\section{Conclusion}

The mobility of perforated plates with varying holes geometries and perforation patterns has been investigated by using Finite Element Method. It is found that the mobility increases as the perforation ratio increases. For a fixed perforation ratio, however, the small hole density (small number, but large diameter holes) gives the most effect to increase vibration at high frequency. The effect can also be seen for holes concentrated in the center of the panel, where vibration can be significantly increased compared to those distributed uniformly or arranged around the plate edges at a fixed perforation ratio. The perforation arrays (either triangular or square) were shown to have insignificant effect on the plate mobility for the same perforation ratio. The same phenomenon is also found for different boundary conditions, that is, free-free and clamped-clamped edges, where the results show a similar trend of the effect of perforation with that from the simply supported edges. The forcing and 


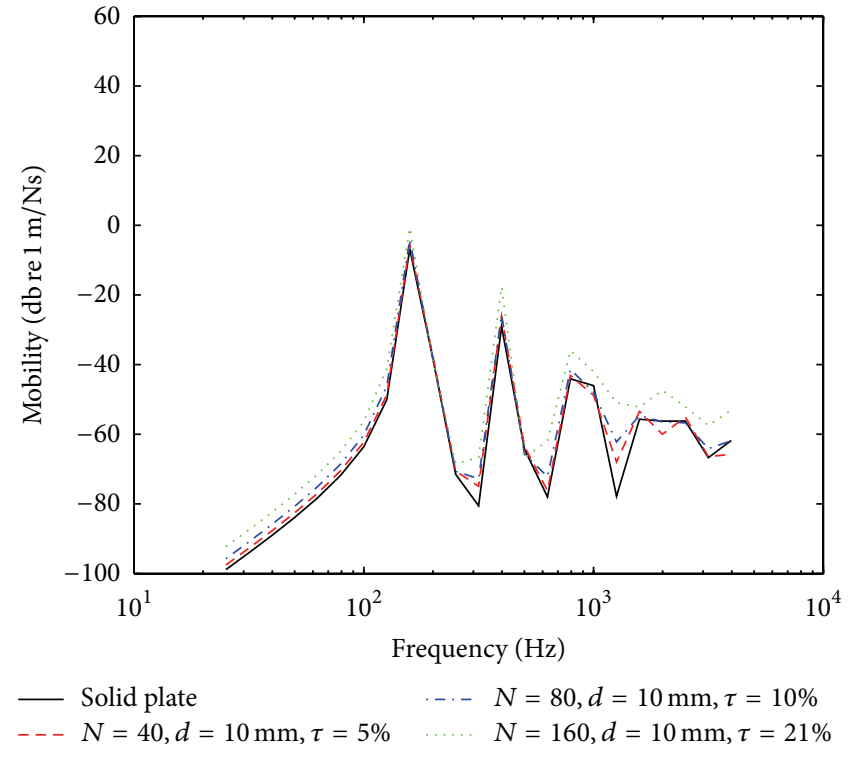

(a)

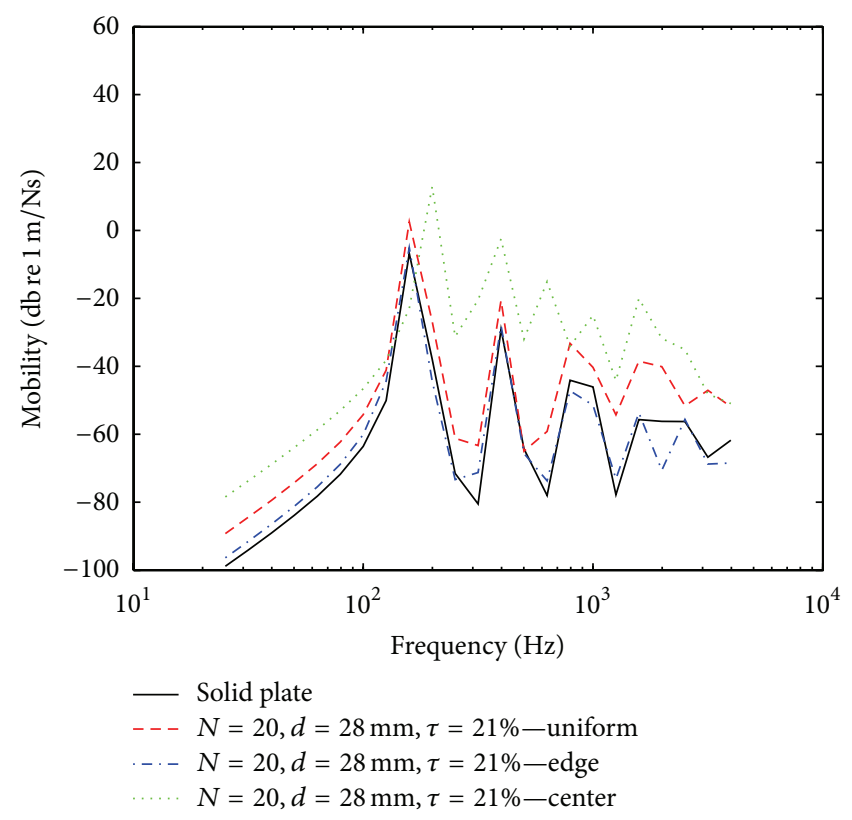

(c)

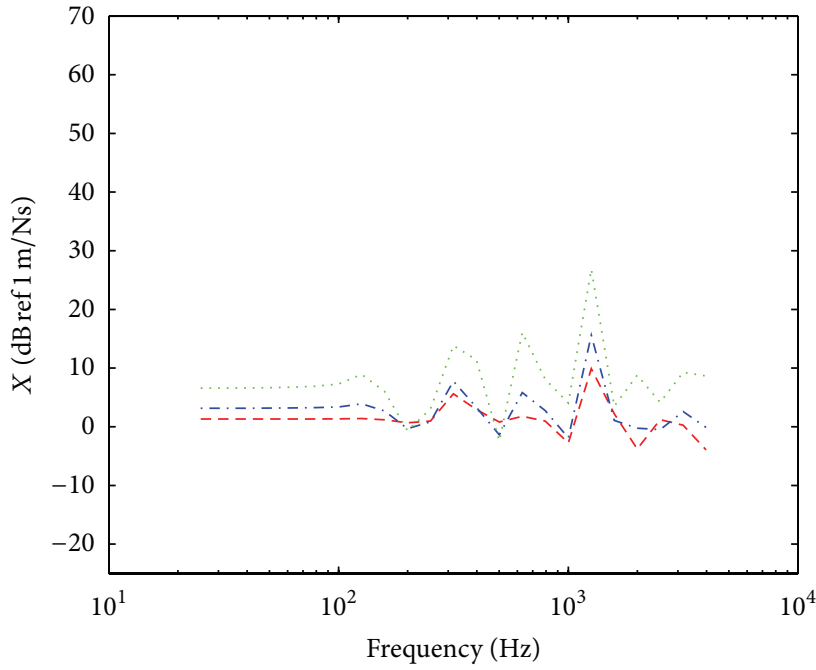

- - $N=40, d=10 \mathrm{~mm}, \tau=5 \% \quad \cdots \quad N=160, d=10 \mathrm{~mm}, \tau=21 \%$ -. $N=80, d=10 \mathrm{~mm}, \tau=10 \%$

(b)

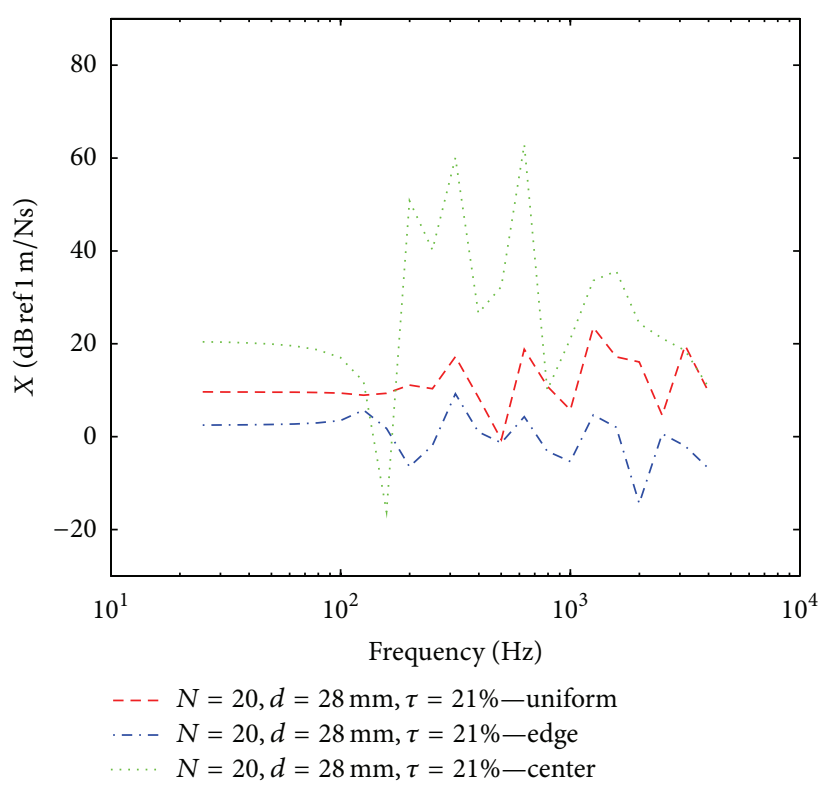

(d)

Figure 15: Mobility ((a), (c)) and effect of perforation ((b), (d)) of the perforated panels for clamped-clamped edges for (a)-(b) fixed hole diameter with increasing perforation ratio and (c)-(d) different arrangement of holes at fixed perforation ratio.

response location at the plate can also give different results. For low perforation ratio or low density (low number of holes per unit area), the mobility is more sensitive around the vicinity of the hole and therefore response location around this area gives higher mobility. As the perforation ratio increases, where the holes become much closer together (higher hole density), the location of the response becomes insensitive to the mobility result. This is due to the global stiffness reduction throughout the individual area of the holes and thus throughout the surface of the plate. All these findings can be used as the general guidance in designing vibrating structures with perforated plates.

\section{Conflict of Interests}

The authors declare that no financial relation exists either directly or indirectly between the authors and the commercial entities mentioned in the paper. 


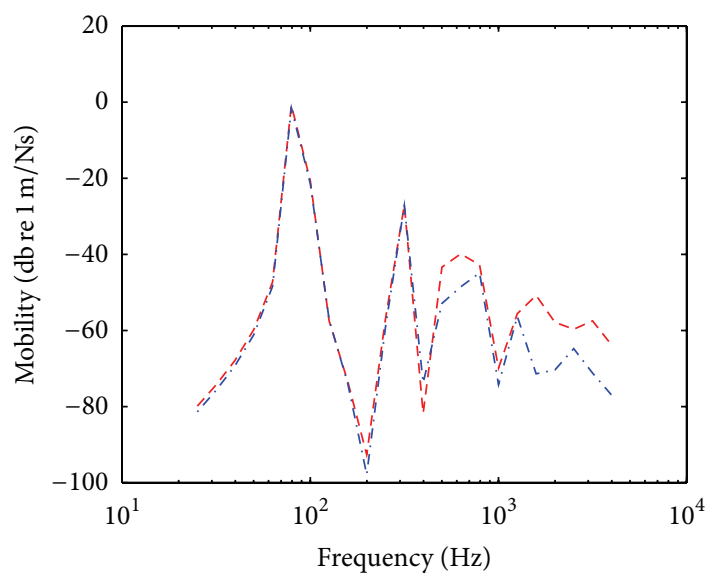

- - $N=40, d=10 \mathrm{~mm}, \tau=5 \%$, point 1

-..- $N=40, d=10 \mathrm{~mm}, \tau=5 \%$, point 2

(a)

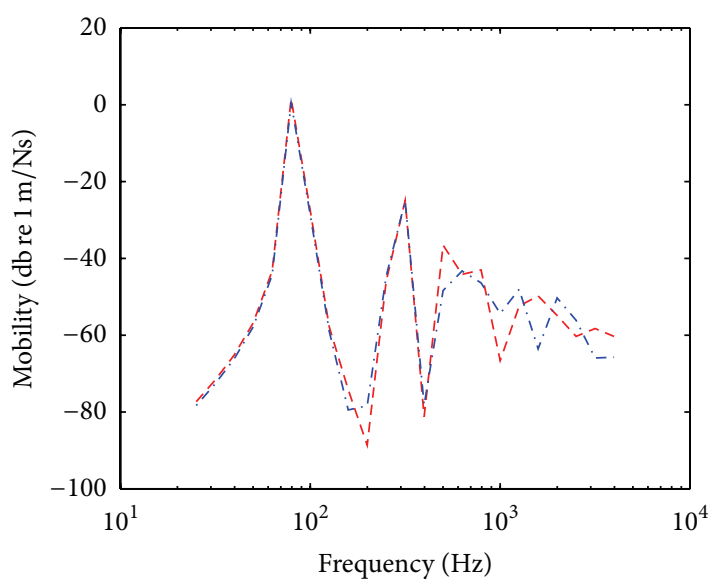

- - $N=40, d=14 \mathrm{~mm}, \tau=10 \%$, point 1

-. - $N=40, d=14 \mathrm{~mm}, \tau=10 \%$, point 2

(c)

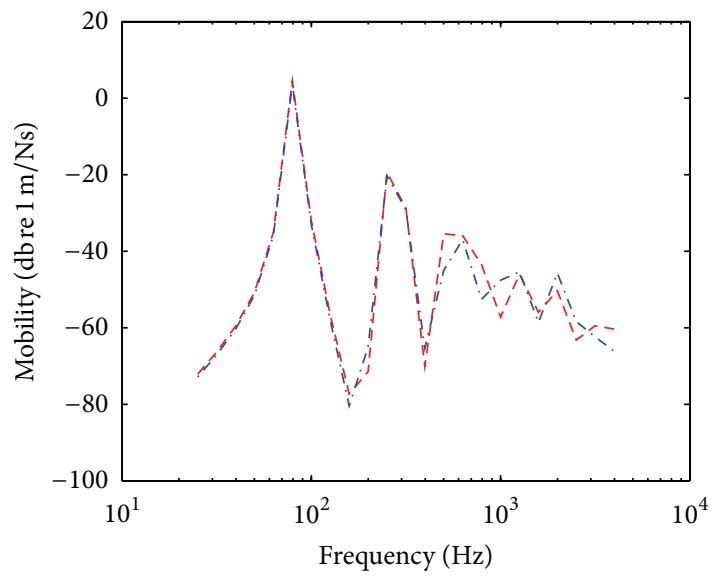

- - $N=40, d=20 \mathrm{~mm}, \tau=21 \%$, point 1

-.. $N=40, d=20 \mathrm{~mm}, \tau=21 \%$, point 2

(e)

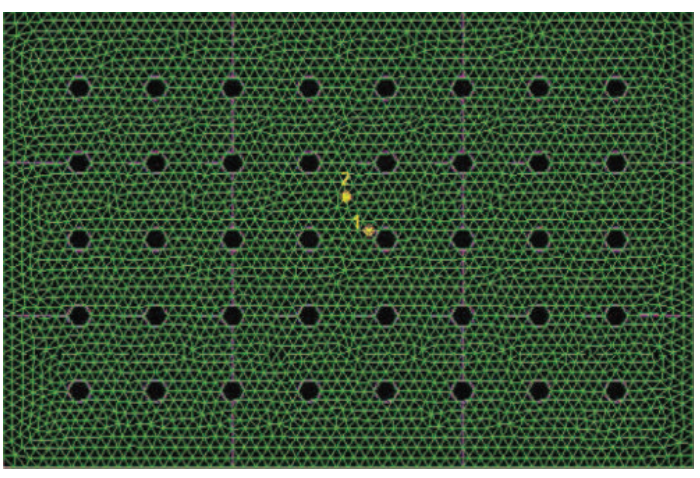

(b)

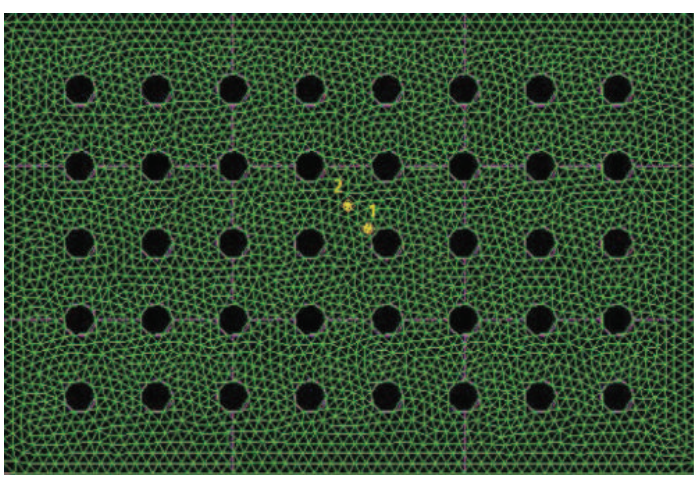

(d)

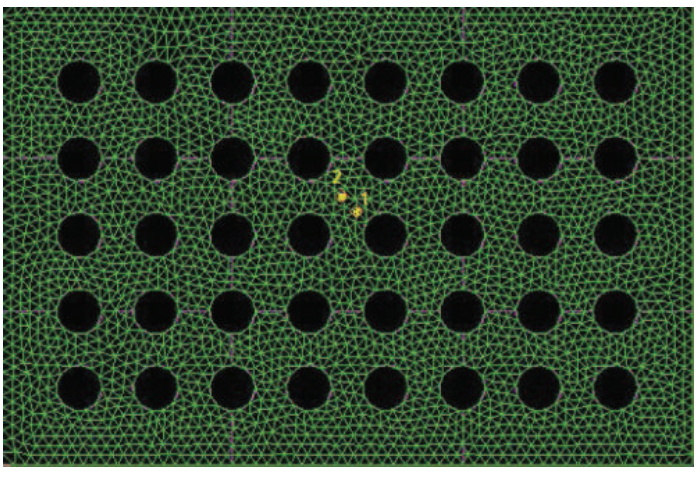

(f)

FIgURE 16: Mobility ((a), (c), and (e)) and different response location ((b), (d), and (f)) at perforated panels. 


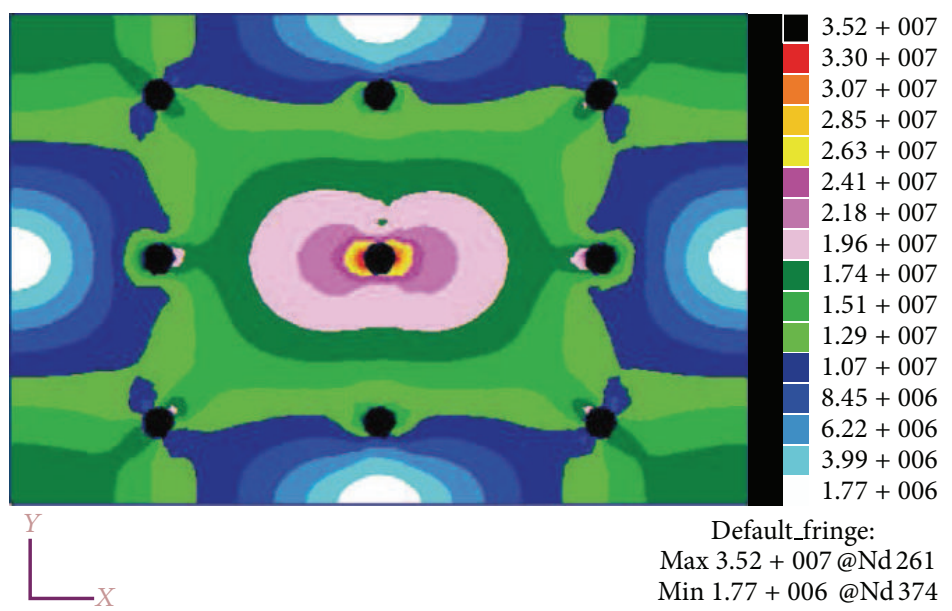

(a)

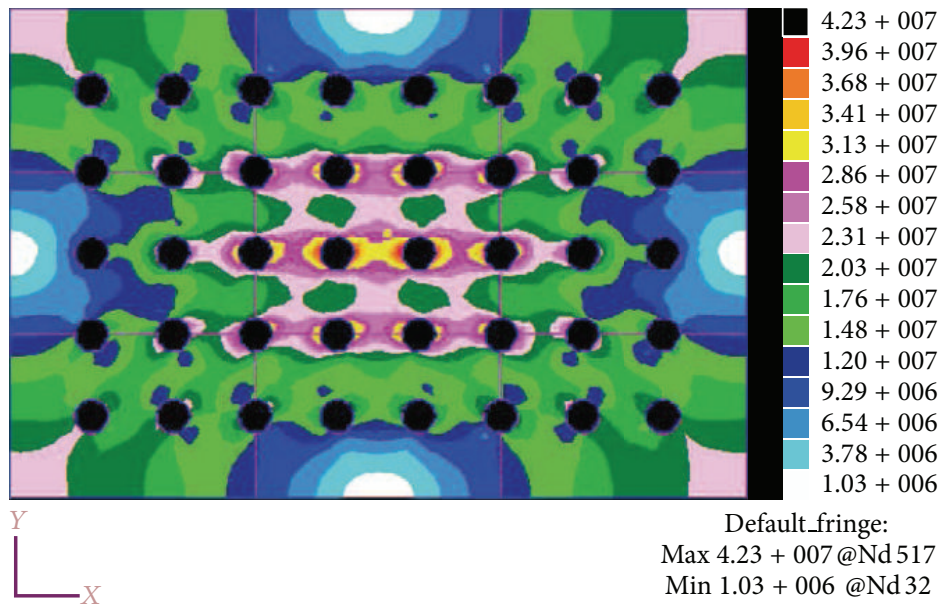

(b)

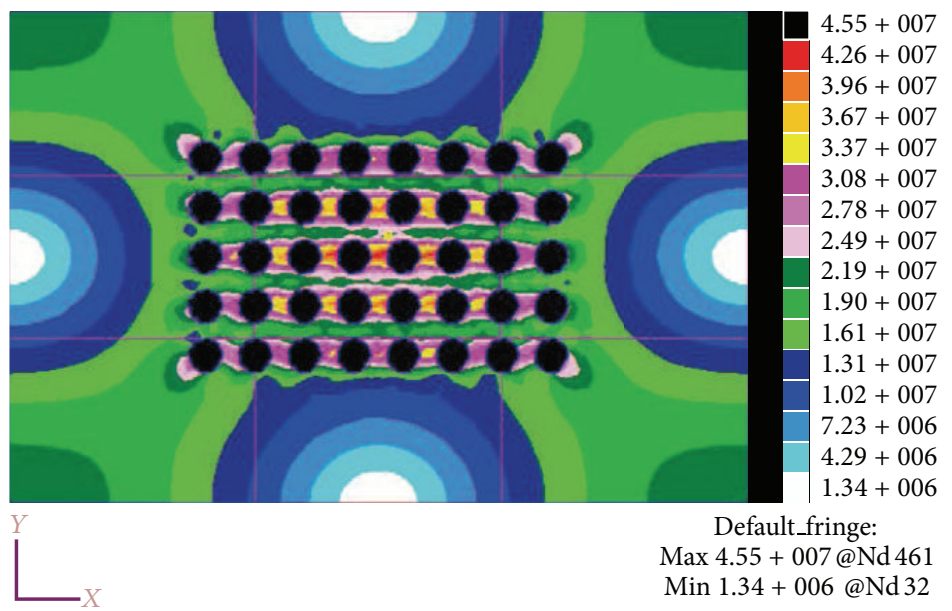

(c)

FIGURE 17: Stress contour of the perforated panels with different hole densities: (a) small hole density, (b) large hole density, and (c) hole concentrated at the center. 


\section{Acknowledgment}

The financial support for this project is provided by the Universiti Teknikal Malaysia Melaka under the Short Term Research Grant no. PJP/2012/FKM (5C)/S01007.

\section{References}

[1] A. Putra and D. J. Thompson, "Sound radiation from perforated plates," Journal of Sound and Vibration, vol. 329, no. 20, pp. 4227-4250, 2010.

[2] A. Putra and D. J. Thompson, "Radiation efficiency of unbaffled and perforated plates near a rigid reflecting surface," Journal of Sound and Vibration, vol. 330, no. 22, pp. 5443-5459, 2011.

[3] R. Bailey and R. Hicks, "Behavior of perforated plates under plane stress," Journal of Mechanical Engineering Science, vol. 2, pp. 143-161, 1960.

[4] W. J. O’Donnel and B. F. Langer, "Design of perforated plates," Journal of Manufacturing Science and Engineering, vol. 84, no. 3, pp. 307-319, 1962.

[5] A. I. Soler and W. S. Hill, "Effective bending properties for stress analysis of rectangular tube sheets," Journal Engineering for Power, vol. 99, no. 3, pp. 365-370, 1977.

[6] M. Forskitt, J. R. Moon, and P. A. Brook, "Elastic properties of plates perforated by cusp-shaped holes," Applied Mathematical Modelling, vol. 15, no. 4, pp. 191-199, 1991.

[7] K. A. Burgemeister and C. H. Hansen, "Calculating resonance frequencies of perforated panels," Journal of Sound and Vibration, vol. 196, no. 4, pp. 387-399, 1996.

[8] D. C. Patil, S. S. Gawade, and K. D. Mali, "Dynamic response analysis of rectangular perforated plates with varying sizes of circular perforation holes," in Proceedings of the 2007 International Congress on Sound and Vibration, Cairns, Australia, July 2007.

[9] K. D. Mali and P. M. Singru, "Determination of the fundamental frequency of perforated rectangular plates: concentrated negative mass approach for the perforation," Advances in Acoustics and Vibration, Article ID 972409, 2013.

[10] P. Gardonio and M. J. Brennan, "Mobility and impedance methods in structural dynamics," in Advanced Applications in Acoustics, Noise and Vibration, F. J. Fahy and J. G. Walker, Eds., chapter 9, CRC Press, 2004.

[11] S. S. Quek and G. R. Liu, Finite Element Method: A Practical Course, vol. 184, 2003.

[12] F. J. Fahy and P. Gardonio, Sound and Structural Vibration: Radiation, Transmission and Response, Academic Press, Oxford, UK, 2007. 

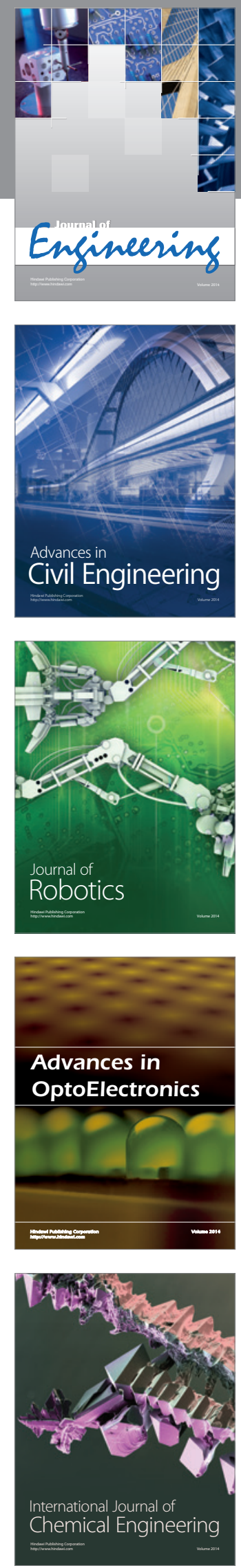

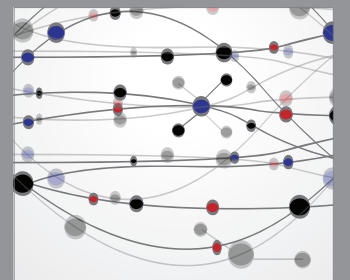

The Scientific World Journal
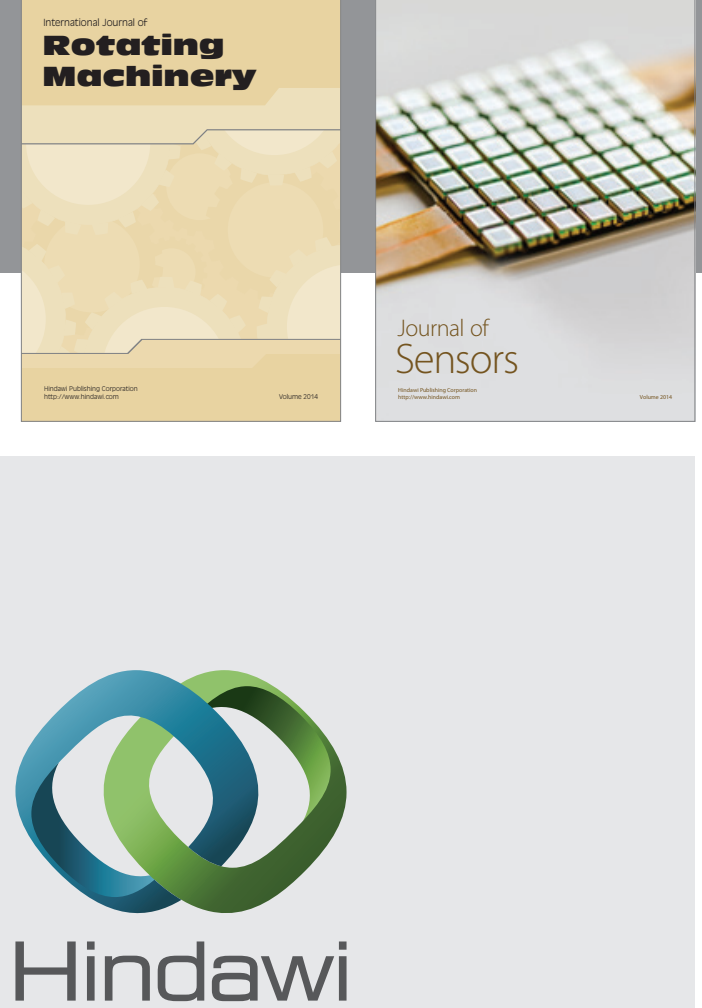

Submit your manuscripts at http://www.hindawi.com
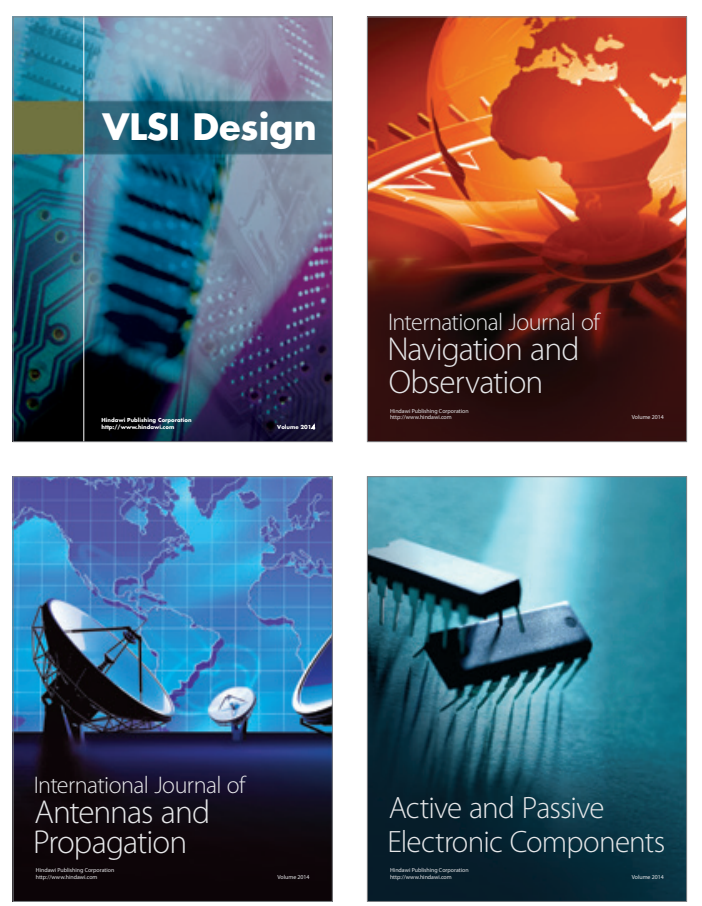
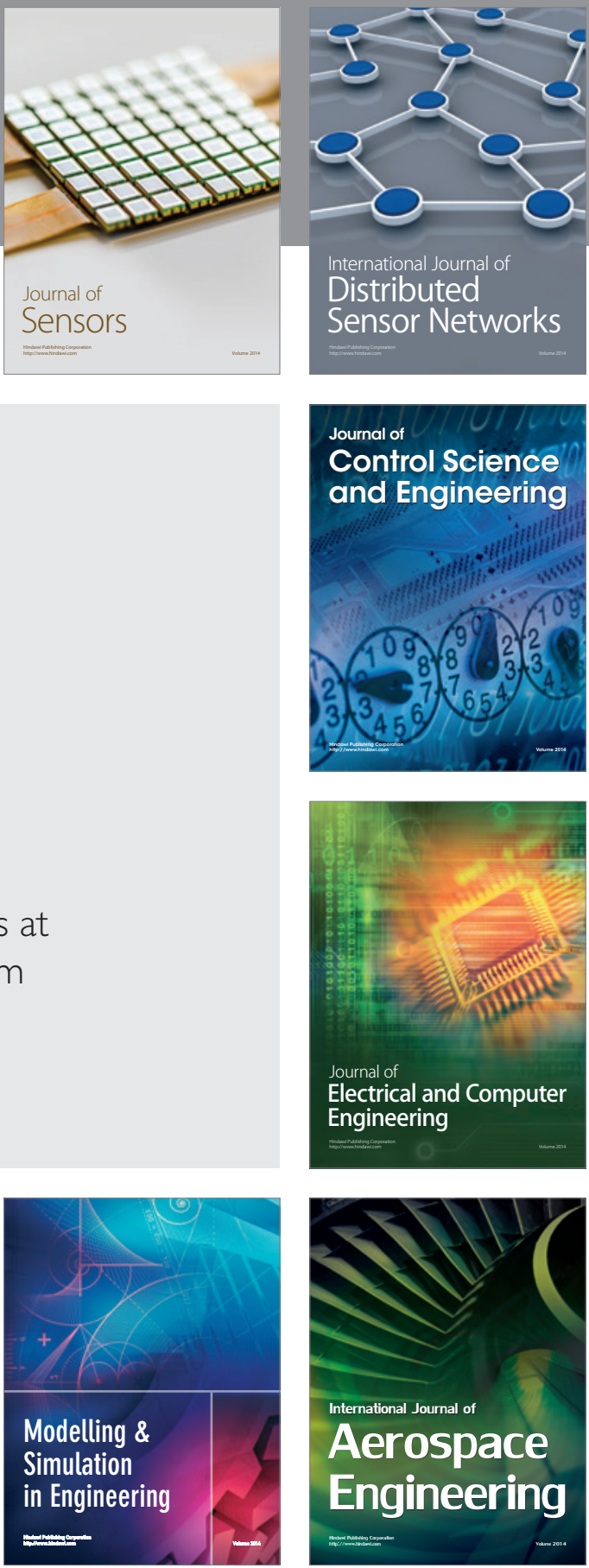

Journal of

Control Science

and Engineering
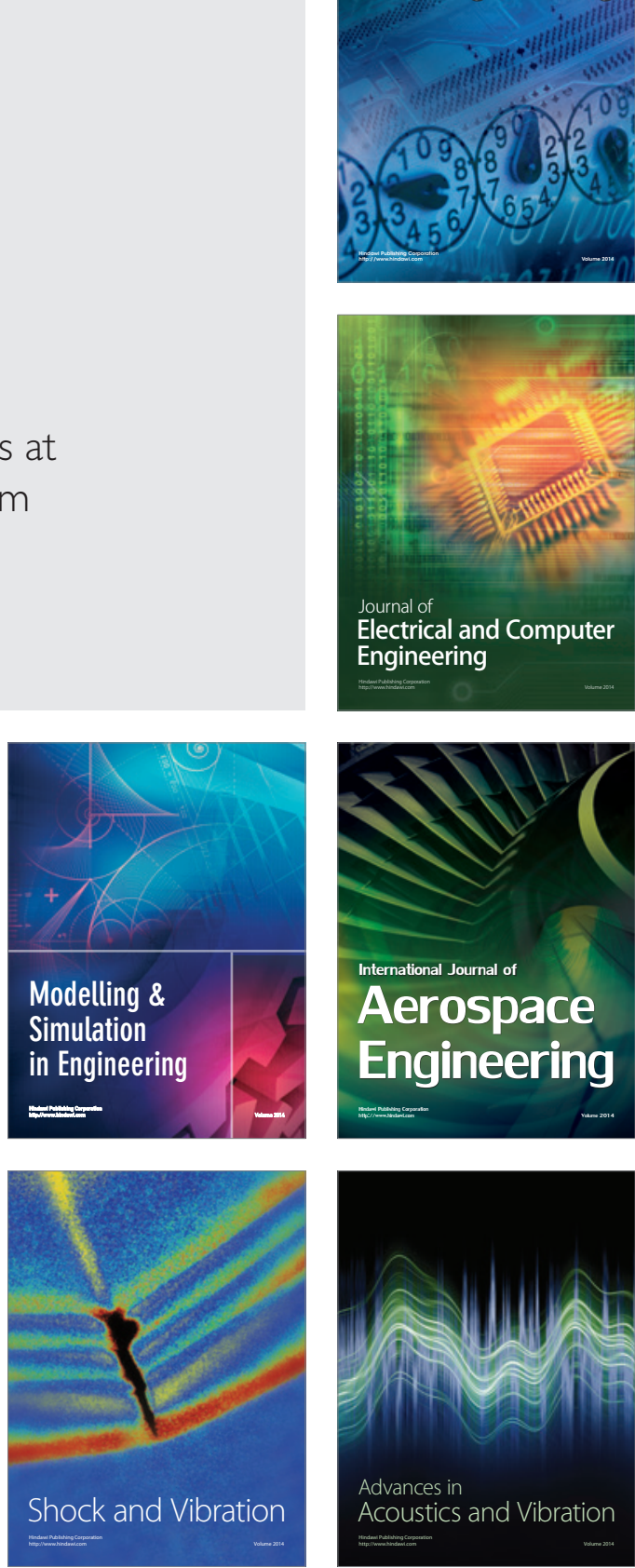